\title{
Design and Implementation of a Loss Optimization Control for Electric Vehicle In-Wheel Permanent-Magnet Synchronous Motor Direct Drive System
}

\author{
Qingbo Guo ${ }^{\mathrm{a}}$, ChengMing Zhang ${ }^{\mathrm{a}}$, Liyi Li $^{\mathrm{a}}$, David Gerada ${ }^{\mathrm{b}}$, Jiangpeng Zhang ${ }^{\mathrm{a}}$, \\ Mingyi Wang ${ }^{\mathrm{a}}$ \\ ${ }^{a}$ Department of Electrical Engineering Harbin Institute of Technology, No. 2 of Yikuang Street, Harbin, 150001. China \\ ${ }^{b}$ PEMC Group, Faculty of Engineering, University of Nottingham, Nottingham, NG72RD. United Kingdom
}

\begin{abstract}
As a main driving force of electric vehicles (EVs), the losses of in-wheel permanent-magnet synchronous motor (PMSM) direct drive system can seriously affect the energy consumption of EVs. This paper proposes a loss minimization control strategy for in-wheel PMSM direct drive system of EVs which optimizes the losses of both the PMSM and of the inverter. The proposed method adjusts the copper losses and iron losses by identifying the optimal flux-weakening current, which results in the PMSM achieving lower losses in the whole operational range. Moreover as there are strongly nonlinear characteristics for the power devices, this paper creates a nonlinear loss model for three-phase half-bridge inverters to obtain accurate inverter losses under space vector pulse width modulation (SVPWM). Based on the inverter loss model and double Fourier integral analysis theory, the PWM frequency is optimized by the control strategy in order to maximize the inverter efficiency without affecting the operational stability of the drive. The proposed loss minimization control strategy can quickly find the optimum flux-weakening current and PWM frequency, and as a result significantly broaden the high efficiency area of the PMSM direct drive system. The effects of the aforementioned strategy are verified by both theoretical analysis and experimental results.
\end{abstract}

\section{HIGHLIGHTS}

(1) The nonlinear characteristics of the power device are modeled.

(2) The harmonic components of a PWM switched inverter output are solved analytically by double Fourier integral analysis theory.

(3) The proposed control strategy can optimize both the motor losses and inverter losses of a PMSM system.

(4) The motor efficiency has been increased by $0.5 \%$, the inverter efficiency has been increased by $6.6 \%$, and the system efficiency has been increased by $4.6 \%$ in a SPMSM system with SiC-MOSFETs.

(5) The proposed loss optimization control strategy has been validated by the experimental tests.

Keywords: SiC-MOSFETs; loss optimization control; nonlinear loss model; analytical harmonic model of inverter output; double Fourier integral analysis; PMSM direct drive system.

\footnotetext{
${ }^{1}$ The short version of the paper was presented at ICAE2016 on Oct 8-11, Beijing, China. This paper is a substantial extension of the short version of the conference paper
} 


\section{Introduction}

With the worldwide shortage of energy and increasingly stringent emission requirements, the improvement of energy efficiency and development of new clean energy have become of increasing importance to society. With the advantage of high energy efficiency and low emissions, electric vehicles (EVs) [1,2] and hybrid electric vehicle (HEVs) [3,4] are considered an attractive proposition to the traditional internal combustion engine vehicles. HEVs are more commonly used for long distance or heavy load transportation while EVs have a stronger application case for transportation within cities. As EVs are a battery-powered, limited energy system, the consumption characteristics of the energy management system are of fundamental importance and an order of magnitude higher in terms of priority compared to HEVs. As regards the system layout, compared to the traditional motor drive system with automated mechanical transmission (AMT) [5], the in-wheel motor direct drive system has the advantages of high dynamic performance and low transmission loss which is more suitable for EVs, as shown in Fig.1.

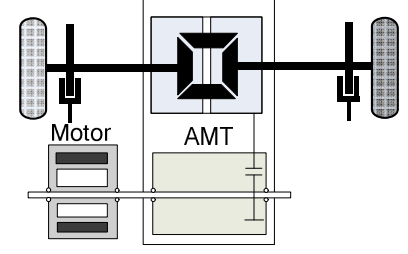

(a)

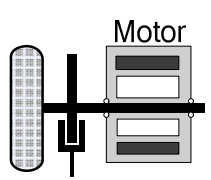

(b)

Fig.1. PMSM drive system in EVs; (a) PMSM with AMT; (b) PMSM direct drive system.

To improve the endurance mileage of EVs in one charge, it is important to minimize the energy consumption. As the main power output mechanism of EVs, any efficiency gains on the traction drive directly translate to a markedly improved endurance mileage[6]. There are several types of electric motor used within the power system of EVs, such as the direct-current (DC) motor, induction motor (IM), permanent magnet synchronous motor (PMSM) and switched reluctance motor (SRM). The PMSM due to its high efficiency, high power factor, and high power density is often the machine of choice. The operational efficiency of the PMSM drive depends on the motor's electromagnetic design and the applied control strategy [7-9]. The electromagnetic design optimization consists of tailoring the constituent geometries, materials and losses with the aim of improving the efficiency at rated operation[10-13]. On the other hand control strategies take into consideration the efficiency within the overall operational range of the drive [14-16]. There are many vector control strategies for PMSM power system of EVs, such as the $i_{d}=0$ control, unity power factor (UPF) control, maximum torque per ampere (MTPA) control, maximum speed per voltage (MSPV) control and loss model control (LMC). The $i_{d}=0$ control maintains the electromagnetic torque and q-axis current in a proportional relationship within the linear machine operation mode by keeping the d-axis current to zero $[17,18]$. The $i_{d}=0$ control is widely used in surface-mounted PMSMs (SPMSMs) due to the lack of saliency. However, $i_{d}=0$ control cannot maximize the electromagnetic torque in interior PMSMs (IPMSMs), and therefore, MTPA control is presented to make the most of the inherent saliency and thus available reluctance torque[19,20]. The MTPA control strategy achieves the minimum copper loss since the least armature current is used to obtain the desired torque output, however it only optimizes for reducing the copper losses and will thus not maximize the efficiency of the PMSM which is constituted of various other loss terms [21-23]. Similarly the MSPV control which minimizes the winding terminal voltage and decreases the iron losses also misses on achieving the maximum machine efficiency. The UPF control 
decreases the reactive power to zero and thus reduces the energy loss between power transmissions [24,25], however in doing so it does not focus on the loss of PMSM and can be thus comparatively inefficient on the machine side[26-30]. The losses of a PMSM can be divided into four parts: mechanical losses, copper losses, iron losses and stray losses. The copper losses and iron losses are so -called controllable losses which can be influenced directly by the control strategies. The MTPA control and MSPV only focus on part of the controllable losses while the LMC takes into consideration both the copper losses and iron losses and can thus optimize for maximizing the efficiency over the whole operational range of the PMSM [31,32].

The literature on LMC focuses attention on the motor loss reduction, however the inverter losses also play an important part in the overall energy consumption characteristics of EVs. Current research on reducing inverter losses focuses on the modulation mode of the three-phase inverter [33-36], and ignores the coupling relations between the power converters and the motors which affect the stability of PMSM system. Other research simply applies SiC power devices to improve the inverter efficiency. Although $\mathrm{SiC}$ power devices with low switching losses decrease the inverter loss and increase the inverter efficiency of the PMSM system, the resulting low efficiency when the vehicle slows down can be an issue in EV applications [37-39]. From the foregoing discussion clearly in optimizing the EV PMSM drive system it is required to take into account the constituent controllable losses of both the machine and the inverter, while carefully considering the stability and dynamic performance requirements.

This paper systematically analyzes the losses of a PMSM drive system in EVs and proposes a novel loss optimization control strategy for PMSM direct drive system which achieves a higher efficiency compared to traditional vector control over the whole vehicle operational range. Based on the loss model of the PMSM, the loss optimization control can optimize the copper losses and iron losses together. In order to characterize the inverter losses accurately, this paper creates a nonlinear loss model of a three-phase half-bridge inverter in the space vector pulse width modulation (SVPWM). This research analyses the harmonic component of pulse width modulation (PWM) output voltage in SVPWM by double Fourier integral analysis, and creates the harmonic model of the PMSM in EVs. Based on the system loss model, the PWM frequency is carefully adjusted to the direct drive system by the proposed control method, which decreases the loss of the inverter while ensuring small current harmonic content. The loss optimization control strategy can reduce the energy consumption without affecting the stability of the PMSM direct drive system for EVs and is validated both theoretically and experimentally.

The remainder of this paper is organized as follows. In Section 2, the model for describing the PMSM direct drive system which considers both the PMSM losses and inverter losses is analysed. In Section 3 , based on the model of PMSM direct drive system, the loss minimization control strategy is developed. In Section 4, the experimental setup is illustrated and the proposed control strategy is validated by experimental results. Conclusions are then drawn in the final section.

\section{Model of PMSM direct drive system}

The typical topology of a PMSM drive system is shown in Fig.2. In order to increase the efficiency of the drivea quantitative power loss analysis is necessary for EVs. Therefore, this paper 
presents a novel loss model of PMSM considers both the motor and inverter losses. Moreover it creates a nonlinear loss model of the three-phase half-bridge inverter which analyses the conduction and switch losses of power devices accurately.

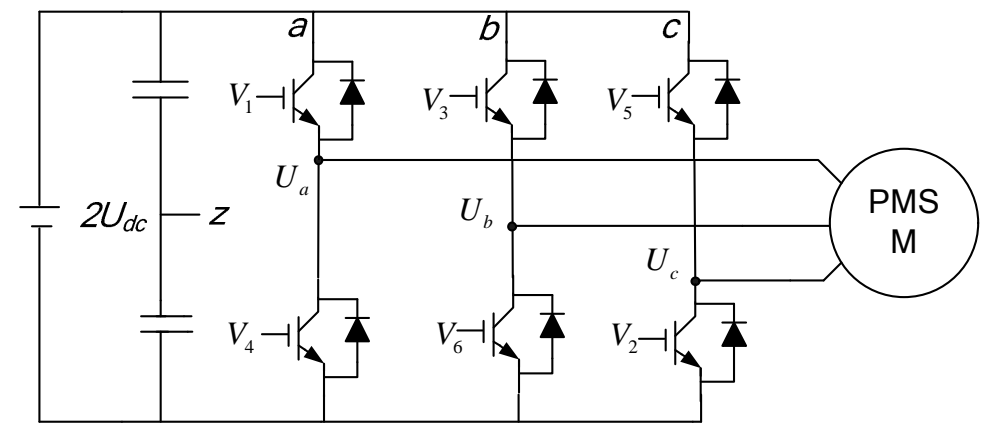

Fig.2. Typical topology of three-phase PMSM power system.

\subsection{Loss model of PMSM}

To minimize the PM motor losses, it is important to build a precise loss model. The controllable loss of PMSM can be divided into two parts, namely the stator copper losses and stator iron losses. The stator copper loss is caused by the motor current in the armature windings while the stator iron loss is generated by the flux linkages in the stator and rotor. The mathematical loss models of a PMSM in the d-axis and q-axis are shown in Fig.3(a) and (b) respecitvely.

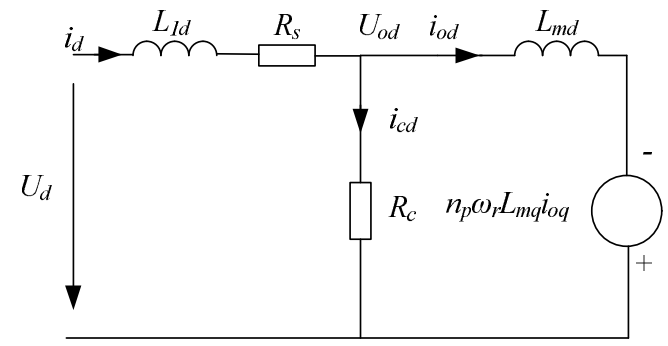

(a)

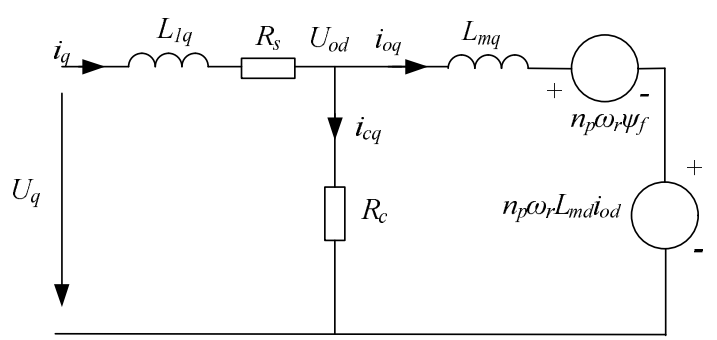

(b)

Fig.3. Decoupled mathematics model of PMSM: (a) Dynamic mathematical model in d-axis; (b) Dynamic mathematical model in q-axis.

From Fig.3, the voltage equations of PMSM can be described as :

$$
\begin{gathered}
{\left[\begin{array}{l}
U_{d} \\
U_{q}
\end{array}\right]=\left[\begin{array}{cc}
L_{1 d} & 0 \\
0 & L_{1 q}
\end{array}\right]\left[\begin{array}{l}
d i_{d} / d t \\
d i_{q} / d t
\end{array}\right]+R_{s}\left[\begin{array}{c}
i_{d} \\
i_{q}
\end{array}\right]+\left[\begin{array}{c}
U_{o d} \\
U_{o q}
\end{array}\right]} \\
{\left[\begin{array}{l}
U_{o d} \\
U_{o q}
\end{array}\right]=\left[\begin{array}{cc}
L_{m d} & 0 \\
0 & L_{m q}
\end{array}\right]\left[\begin{array}{l}
d i_{o d} / d t \\
d i_{o q} / d t
\end{array}\right]+\left[\begin{array}{cc}
0 & -n_{p} \omega_{r} L_{m q} \\
n_{p} \omega_{r} L_{m d} & 0
\end{array}\right]\left[\begin{array}{l}
i_{o d} \\
i_{o q}
\end{array}\right]+\left[\begin{array}{c}
0 \\
n_{p} \omega_{r} \psi_{f}
\end{array}\right]}
\end{gathered}
$$

where $L_{1 d}$ and $L_{1 q}$ are the stator leakage inductances in the d-axis and q-axis, $L_{m d}$ and $L_{m q}$ are the stator self inductances in the d-axis and q-axis respectively, $R_{s}$ is the stator armature resistance, $R_{c}$ is the stator iron loss resistance, $n_{p}$ is the pole pair number, $\omega_{r}$ is the rotational speed, $\psi_{f}$ is the magnet flux linkage, $u_{d, q}$ and $i_{d, q}$ are the stator terminal voltage and the armature current respectively, $i_{c d}$ and $i_{c q}$ are the iron loss currents, while $i_{o d}$ and $i_{o q}$ are the magnetic currents in the d-axis and q-axis respectively.

From equations (1) and (2), the current equations can be derived as : 


$$
\left\{\begin{array}{c}
i_{o d}=i_{d}-i_{c d} \\
i_{o q}=i_{q}-i_{c q} \\
i_{c d}=u_{o d} / R_{c}=\left(L_{m d} d i_{o d} / d t-n_{p} \omega_{r} L_{q} i_{o q}\right) / R_{c} \\
i_{c q}=u_{o q} / R_{c}=\left[L_{m q} d i_{o q} / d t+n_{p} \omega_{r}\left(\psi_{f}+L_{d} i_{o d}\right)\right] / R_{c}
\end{array}\right.
$$

Based on the voltage and current equations, the stator copper loss can be obtained as :

$$
\begin{aligned}
P_{C u} & =1.5 R_{s}\left(i_{d}^{2}+i_{q}^{2}\right) \\
& =1.5 R_{s}\left\{\begin{array}{l}
\left(i_{o d}+\left(L_{m d} d i_{o d} / d t-n_{p} \omega_{r} L_{q} i_{o q}\right) / R_{c}\right)^{2} \\
+\left[i_{o q}+\left(L_{m q} d i_{o q} / d t+n_{p} \omega_{r}\left(\psi_{f}+L_{d} i_{o d}\right)\right) / R_{c}\right]^{2}
\end{array}\right\}
\end{aligned}
$$

where the coefficient 1.5 in (4) is a result of the Clark and Park transformations, in which the flux value remains invariable

The stator iron loss of PMSM can be also described as :

$$
\begin{aligned}
P_{F e} & =1.5 R_{c}\left(i_{c d}^{2}+i_{c q}^{2}\right) \\
& =1.5\left(L_{m d} d i_{o d} / d t-n_{p} \omega_{r} L_{q} i_{o q}\right)^{2} / R_{c} \\
& +1.5\left[L_{m q} d i_{o q} / d t+n_{p} \omega_{r}\left(\psi_{f}+L_{d} i_{o d}\right)\right]^{2} / R_{c}
\end{aligned}
$$

From equation (4) and equation (5), the fundamental loss can then be derived as :

$$
\begin{aligned}
P_{\text {loss_motor }}= & P_{C u}+P_{F e} \\
= & 1.5 R_{s}\left(i_{o d}+\left(L_{m d} d i_{o d} / d t-n_{p} \omega_{r} L_{q} i_{o q}\right) / R_{c}\right)^{2} \\
& +1.5 R_{s}\left[i_{o q}+\left(L_{m q} d i_{o q} / d t+n_{p} \omega_{r}\left(\psi_{f}+L_{d} i_{o d}\right)\right) / R_{c}\right]^{2} \\
& +1.5\left(L_{m d} d i_{o d} / d t-n_{p} \omega_{r} L_{q} i_{o q}\right)^{2} / R_{c} \\
& +1.5\left[L_{m q} d i_{o q} / d t+n_{p} \omega_{r}\left(\psi_{f}+L_{d} i_{o d}\right)\right]^{2} / R_{c}
\end{aligned}
$$

The major energy loss occurs at steady state conditions, hence (6) can be simplified as :

$$
\begin{aligned}
P_{\text {loss } \_ \text {motor }} & =P_{\mathrm{Cu}_{-} f}+P_{\mathrm{Fe}_{-} f} \\
& =1.5 R_{s}\left\{\left(i_{o d}-n_{p} \omega_{r} L_{q} i_{o q} / R_{c}\right)^{2}+\left[i_{o q}+n_{p} \omega_{r}\left(\psi_{f}+L_{d} i_{o d}\right) / R_{c}\right]^{2}\right\} \\
& +1.5\left(n_{p} \omega_{r} L_{q} i_{o q}\right)^{2} / R_{c}+1.5\left[n_{p} \omega_{r}\left(\psi_{f}+L_{d} i_{o d}\right)\right]^{2} / R_{c}
\end{aligned}
$$

From equation (7) the motor loss is only a function of the rotational speed, d-axis current and q-axis current.

\subsection{Loss model of three-phase half-bridge inverter}

This section proposes a novel model of the power device which considers the nonlinear characteristics of both the switching and conduction losses and uses these to analytically predict the nonlinear losses of the sinusoidal PMSM power converter under SVPWM fast and precisely. 


\subsubsection{Inverter Conduction Losses}

As shown in Fig.4, there is a high degree of nonlinearity in both the switching and conduction characteristics of power devices such as MOSFETs and IGBTs. The classical linear model of conduction characteristics is expressed as :

$$
u_{\text {cesat }}=U_{t 0}+R_{d s} \cdot i_{c e}
$$

where $u_{\text {cesat }}$ is the saturation voltage of the power device, $U_{t 0}$ is the equivalent conduction voltage at rated current $I_{n}, i_{c e}$ is the current through power device, and $R_{c e}$ is the equivalent conduction resistance at the rated current $I_{n}$. The main drawback of the aforesaid linear model is that it can only calculate losses accurately close to the rated current. As the stator current in the PMSM EV drive changes continuously in a sinusoidal manner a more representative model is required.

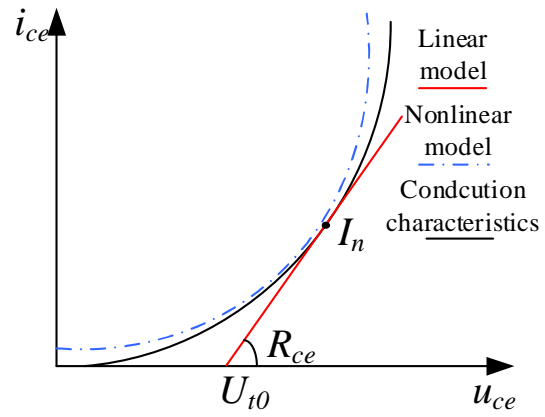

Fig.4. Conduction characteristics of the power devices

From Fig.4. the nonlinear model for the power device conduction characteristics is more representatively described for the whole operational range by a second order polynomial of the form :

$$
u_{\text {cesat }}=a_{c}+b_{c} i_{c e}+c_{c} i_{c e}^{2}
$$

where $a_{c}, b_{c}$ and $c_{c}$ are fitting coefficients.

The average conduction losses of the power device in a current period can then be expressed as :

$$
P_{\text {loss_conduction }}=\int_{0}^{T_{\text {current }}} d_{c e} \cdot u_{c e} \cdot i_{c e} d t / T_{\text {current }}
$$

where $T_{\text {current }}$ is the current period, and $d_{c e}$ is the duty ratio of PWM signal.

\subsubsection{Inverter Switching Losses}

As with the conduction effects, the switching losses are also highly nonlinear. These can be divided into two constituent parts namely (i)switch-on loss and (ii)switch-off loss. The nonlinear models for the switching loss characteristics of the power device can also be described by second order polynomials :

$$
\begin{aligned}
& E_{o n}=2 U_{d c} \cdot\left(a_{o n}+b_{o n} \cdot i_{c e}+c_{o n} \cdot i_{c e}^{2}\right) / U_{d c_{-} t e s t} \\
& E_{o f f}=2 U_{d c} \cdot\left(a_{o f f}+b_{o f f} \cdot i_{c e}+c_{o f f} \cdot i_{c e}^{2}\right) / U_{d c_{-} \text {test }}
\end{aligned}
$$

where $2 U_{d c}$ is the DC voltage, $U_{d c_{-} \text {test }}$ is the DC voltage when the chip manual tested switching characteristics of the power device while $a_{o n}, b_{o n}, c_{o n}, a_{o f f}, b_{o f f}$ and $c_{o f f}$ are fitting coefficients. 
As the switching losses are a function of current, for the sinusoidal EV drive under consideration the losses in a current period can be expressed as :

$$
P_{\text {loss_switch }}=\int_{0}^{T_{\text {current }}}\left(E_{\text {on }}+E_{\text {off }}\right) d t / T_{\text {current }}
$$

\subsubsection{Loss model under SVPWM}

Based on the described conduction and switching loss models of the power device, the loss model of a three-phase inverter can be obtained for different modulation modes. As shown in Fig.5, there are only eight possible switch combinations for a three-phase inverter.

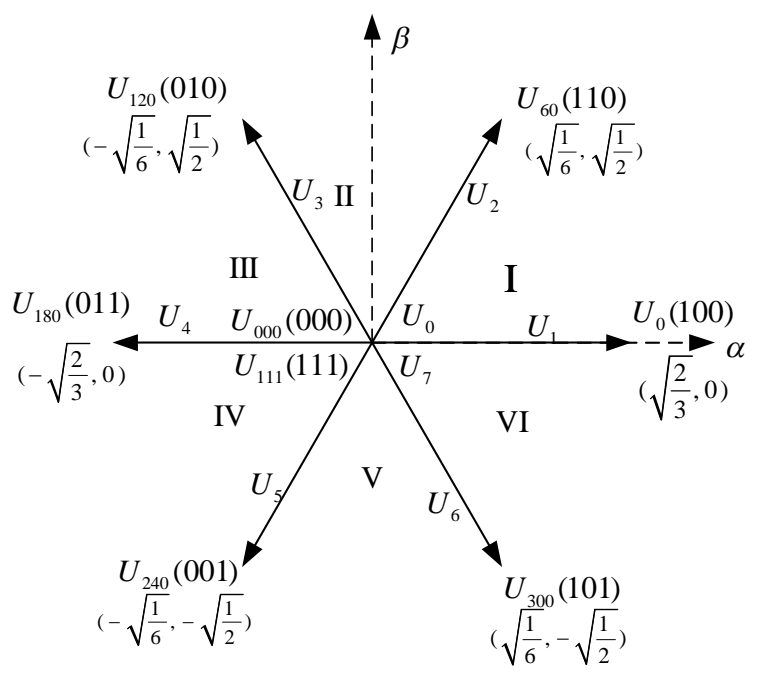

Fig.5. Eight switch states for three-phase inverter.

The state of a phase leg is defined as " 1 " when the phase leg is open, and as " 0 " when closed. The $\mathrm{U}_{0}$ (000) state and U7 (111) state correspond to a short circuit on the output, while the other six states can be considered to form stationary vectors in the d-q complex plane. Each stationary vector corresponds to a particular fundamental angular position. The SVPWM applies these eight stationary vectors to form an arbitrary target output vector $\mathrm{U}_{0}$ at any point in time by the summation of a number of these space vectors within one switching period (TPWM). The space vectors and active times for different target output vectors is shown in Table 1.

Based on Table 1, the duty ratio of a PWM signal on the power device can be calculated by the space vector active time in SVPWM., hence the conduction loss of an IGBT in the three-phase half-bridge inverter can be expressed as :

$$
\begin{aligned}
P_{\text {loss_conduction }} & =\int_{0}^{T_{\text {current }}} d_{c e} \cdot\left(a_{c}+b_{c} i_{c e}+c_{c} i_{c e}^{2}\right) \cdot i_{c e} d t / T_{\text {current }} \\
& =\int_{0}^{T_{\text {current }} / 2} d_{c e} \cdot\left[a_{c}+b_{c} I_{0} \cdot \sin \omega_{\text {current }} t+c_{c}\left(I_{0} \cdot \sin \omega_{\text {current }} t\right)^{2}\right] \cdot\left(I_{0} \cdot \sin \omega_{\text {current }} t\right) \cdot d t / T_{\text {current }} \\
& =I_{0}\left[\begin{array}{l}
\left.24 a_{c}+16 c_{c} I_{0}^{2}+6 \pi b_{c} I_{0}-6 b_{c} I_{0} m-\frac{9}{8} c_{c} I_{0}^{2} m \cos (3 \varphi)-4 b_{c} I_{0} m \cos (2 \varphi)\right] / 48 \\
+4 \sqrt{3} \pi a_{c} m \cos \varphi+16 \sqrt{3} b_{c} I_{0} m \cos \varphi+3 \sqrt{3} \pi c_{c} I_{0}^{2} m \cos \varphi
\end{array}\right] / 4
\end{aligned}
$$


where $I_{0}$ is the amplitude of the motor's sinusoidal phase current, $\omega_{\text {current }}$ is the current's angular frequency, $\varphi$ is the power factor angle and $m$ is the modulation ratio for SVPWM, defined as :

$$
m=\sqrt{3} U_{0} / 2 U_{d c}
$$

where $U_{0}$ is the line-to-line voltage amplitude.

Table 1. Space vector and active time in the SVPWM.

\begin{tabular}{ccc}
\hline $\boldsymbol{\omega}_{\mathbf{0}} \mathbf{t}=\boldsymbol{\theta}_{\mathbf{0}}$ & Space vector & Space vector active time \\
\hline \multirow{2}{*}{$0 \theta_{0}<\pi / 3$} & $U_{1}$ & $T_{U 1}=\sqrt{3} U_{0} \cos \left(\theta_{0}+\pi / 6\right) T_{P W M} / 2 U_{d c}$ \\
& $U_{2}$ & $T_{U 2}=\sqrt{3} U_{0} \cos \left(\theta_{0}-\pi / 2\right) T_{P W M} / 2 U_{d c}$ \\
$\pi / 3 \leq \theta_{0}<2 \pi / 3$ & $U_{2}$ & $T_{U 2}=\sqrt{3} U_{0} \cos \left(\theta_{0}-\pi / 6\right) T_{P W M} / 2 U_{d c}$ \\
$2 \pi / 3 \leq \theta_{0}<\pi$ & $U_{3}$ & $T_{U 3}=\sqrt{3} U_{0} \cos \left(\theta_{0}-5 \pi / 6\right) T_{P W M} / 2 U_{d c}$ \\
& $U_{3}$ & $T_{U 3}=\sqrt{3} U_{0} \cos \left(\theta_{0}-\pi / 2\right) T_{P W M} / 2 U_{d c}$ \\
$\pi \leq \theta_{0}<4 \pi / 3$ & $U_{4}$ & $T_{U 4}=\sqrt{3} U_{0} \cos \left(\theta_{0}-7 \pi / 6\right) T_{P W M} / 2 U_{d c}$ \\
& $U_{4}$ & $T_{U 4}=\sqrt{3} U_{0} \cos \left(\theta_{0}-5 \pi / 6\right) T_{P W M} / 2 U_{d c}$ \\
$4 \pi / 3 \leq \theta_{0}<5 \pi / 3$ & $U_{5}$ & $T_{U 5}=\sqrt{3} U_{0} \cos \left(\theta_{0}-3 \pi / 2\right) T_{P W M} / 2 U_{d c}$ \\
& $U_{5}$ & $T_{U 5}=\sqrt{3} U_{0} \cos \left(\theta_{0}-7 \pi / 6\right) T_{P W M} / 2 U_{d c}$ \\
$5 \pi / 3 \leq \theta_{0}<2 \pi$ & $U_{6}$ & $T_{U 6}=\sqrt{3} U_{0} \cos \left(\theta_{0}-11 \pi / 6\right) T_{P W M} / 2 U_{d c}$ \\
& & $T_{U 6}=\sqrt{3} U_{0} \cos \left(\theta_{0}-3 \pi / 2\right) T_{P W M} / 2 U_{d c}$ \\
& $U_{6}$ & $T_{U 1}=\sqrt{3} U_{0} \cos \left(\theta_{0}-\pi / 6\right) T_{P W M} / 2 U_{d c}$ \\
\hline
\end{tabular}

The conduction loss of the freewheeling diode (FWD), switching loss of IGBT, and recovery loss of FWD can be calculated in the similar way to conduction loss of IGBT. Therefore, the nonlinear loss model of the power converter under SVPWM can be expressed as :

$$
\begin{aligned}
& P_{\text {loss_power }}=6 \cdot\left(P_{I G B T}+P_{F W D}\right) \\
& =6\left\{\begin{array}{l}
{\left[\begin{array}{l}
24\left(a_{c}+a_{f}\right)+16\left(c_{c}+c_{f}\right) I_{0}^{2}+6 \pi\left(b_{c}+b_{f}\right) I_{0}-6\left(b_{c}-b_{f}\right) I_{0} m \\
-9 / 8\left(c_{c}-c_{f}\right) I_{0}^{2} m \cos (3 \varphi)-4\left(b_{c}-b_{f}\right) I_{0} m \cos (2 \varphi) \\
I_{0} \\
+4 \sqrt{3} \pi\left(a_{c}-a_{f}\right) m \cos \varphi+16 \sqrt{3}\left(b_{c}-b_{f}\right) I_{0} m \cos \varphi \\
+3 \sqrt{3} \pi\left(c_{c}-c_{f}\right) I_{0}^{2} m \cos \varphi \\
+2 f_{\text {sw }} U_{d c} \cdot\left[\left(c_{\text {on }}+c_{\text {off }}+c_{\text {rec }}\right) I_{0}^{2} / 4+\left(b_{\text {on }}+b_{\text {off }}+b_{\text {rec }}\right) I_{0} / \pi+\left(a_{o n}+a_{\text {off }}+a_{\text {rec }}\right) / 2\right] / U_{d c_{\text {_test }}}
\end{array}\right] / 48 \pi}
\end{array}\right.
\end{aligned}
$$

where $P_{F W D}$ is the loss of freewheeling diode. $a_{f}, b_{f}$ and $c_{f}$ are the fitting coefficients for conduction characteristics of FWD. $a_{r e c}, b_{r e c}$, and $c_{r e c}$ are the fitting coefficients for recovery characteristics of FWD. and $f_{s w}$ is the PWM frequency.

\section{Loss optimization control strategy}

From the previous sections discussing the loss models of the motor and PE converter, it can be seen that the loss of the direct drive system in consideration is a fairly complex function, as described by equation (17) : 


$$
\begin{aligned}
& P_{\text {loss_ssstem }}=P_{\text {loss_motor }}+P_{\text {loss_power }} \\
& =6\left\{\begin{array}{l}
{\left[\begin{array}{l}
24\left(a_{c}+a_{f}\right)+16\left(c_{c}+c_{f}\right) I_{0}^{2}+6 \pi\left(b_{c}+b_{f}\right) I_{0}-6\left(b_{c}-b_{f}\right) I_{0} m \\
-9 / 8\left(c_{c}-c_{f}\right) I_{0}^{2} m \cos (3 \varphi)-4\left(b_{c}-b_{f}\right) I_{0} m \cos (2 \varphi) \\
+4 \sqrt{3} \pi\left(a_{c}-a_{f}\right) m \cos \varphi+16 \sqrt{3}\left(b_{c}-b_{f}\right) I_{0} m \cos \varphi \\
+3 \sqrt{3} \pi\left(c_{c}-c_{f}\right) I_{0}^{2} m \cos \varphi
\end{array}\right] / 48 \pi} \\
+2 f_{s w} U_{d c} \cdot\left[\left(c_{o n}+c_{o f f}+c_{\text {rec }}\right) I_{0}^{2} / 4+\left(b_{o n}+b_{o f f}+b_{\text {rec }}\right) I_{0} / \pi+\left(a_{o n}+a_{o f f}+a_{r e c}\right) / 2\right] / U_{d c_{-} \text {test }}
\end{array}\right\} \\
& +1.5 R_{s}\left\{\left(i_{o d}-n_{p} \omega_{r} L_{q} i_{o q} / R_{c}\right)^{2}+\left[i_{o q}+n_{p} \omega_{r}\left(\psi_{f}+L_{d} i_{o d}\right) / R_{c}\right]^{2}\right\} \\
& +1.5\left(n_{p} \omega_{r} L_{q} i_{o q}\right)^{2} / R_{c}+1.5\left[n_{p} \omega_{r}\left(\psi_{f}+L_{d} i_{o d}\right)\right]^{2} / R_{c}
\end{aligned}
$$

where $I_{0}$ can be obtained as :

$$
\begin{aligned}
I_{0} & =\sqrt{i_{d}^{2}+i_{q}^{2}} \\
& =\sqrt{\begin{array}{l}
{\left[\left(L_{m d} d i_{o d} / d t-n_{p} \omega_{r} L_{q} i_{o q}\right) / R_{c}+i_{o d}\right]^{2}} \\
+\left\{\left[L_{m q} d i_{o q} / d t+n_{p} \omega_{r}\left(\psi_{f}+L_{d} i_{o d}\right)\right] / R_{c}+i_{o q}\right\}^{2}
\end{array}}
\end{aligned}
$$

The power factor $\varphi$ can be calculated from :

$$
\varphi=\arctan \left(u_{d} / u_{q}\right)-\arctan \left(i_{d} / i_{q}\right)
$$

Due to the complexity of the loss model it is impossible to obtain the optimal working point by means of direct analysis. In light of the aforesaid this paper proposes a quick and simple loss minimization control strategy which divides the system losses into two parts, namely (i)the losses affected by PMSM operation condition and (ii) the losses affected by the inverter state :

$$
P_{\text {loss_system }}=P_{\text {loss_PMSM }}+P_{\text {loss_inverter }}
$$

The loss affected by the PMSM operation condition can be written as :

$$
\begin{aligned}
P_{\text {loss_PMSM }}=I_{0}\left[\begin{array}{l}
24\left(a_{c}+a_{f}\right)+16\left(c_{c}+c_{f}\right) I_{0}^{2}+6 \pi\left(b_{c}+b_{f}\right) I_{0}-6\left(b_{c}-b_{f}\right) I_{0} m \\
-9 / 8\left(c_{c}-c_{f}\right) I_{0}^{2} m \cos (3 \varphi)-4\left(b_{c}-b_{f}\right) I_{0} m \cos (2 \varphi) \\
+4 \sqrt{3} \pi\left(a_{c}-a_{f}\right) m \cos \varphi+16 \sqrt{3}\left(b_{c}-b_{f}\right) I_{0} m \cos \varphi \\
+3 \sqrt{3} \pi\left(c_{c}-c_{f}\right) I_{0}^{2} m \cos \varphi
\end{array}\right] / 8 \pi \\
+1.5 R_{s}\left\{\left(i_{o d}-n_{p} \omega_{r} L_{q} i_{o q} / R_{c}\right)^{2}+\left[i_{o q}+n_{p} \omega_{r}\left(\psi_{f}+L_{d} i_{o d}\right) / R_{c}\right]^{2}\right\} \\
+1.5\left(n_{p} \omega_{r} L_{q} i_{o q}\right)^{2} / R_{c}+1.5\left[n_{p} \omega_{r}\left(\psi_{f}+L_{d} i_{o d}\right)\right]^{2} / R_{c}
\end{aligned}
$$

while the loss affected by the inverter state can be expressed as :

$$
P_{\text {loss_inverter }}=12 f_{\text {sw }} U_{d c} \cdot\left[\left(c_{\text {on }}+c_{\text {off }}+c_{\text {rec }}\right) I_{0}^{2} / 4+\left(b_{\text {on }}+b_{\text {off }}+b_{\text {rec }}\right) I_{0} / \pi+\left(a_{o n}+a_{o f f}+a_{\text {rec }}\right) / 2\right] / U_{d c_{-} \text {test }}
$$

The proposed control method can improve the system efficiency by optimizing these two parts of system loss in an analytical manner. In addition, the coupling relation between motor and inverter is also considered by the loss minimization control strategy.

\subsection{Optimization on the loss affected by PMSM state}


From equation (21) $\mathrm{P}_{\text {loss_PMSM }}$ consists of inverter conduction losses together with the PMSM losses. Compared with motor loss, the inverter conduction loss is much smaller in magnitude and hence can be ignored for efficiency optimization purposes. Equation (21) also shows that the controllable part of loss affected by PMSM state is a function of d-axis magnetic current $i_{o d}$, angular speed $\omega_{r}$ and q-axis magnetic current $i_{o q}$ :

$$
P_{\text {loss_PMSM }}=f\left(i_{\text {od }}, \omega_{r}, i_{o q}\right)
$$

The electromagnetic torque equation of PMSM can be described as

$$
T_{e}=1.5 n_{p}\left[\psi_{f} i_{o q}+\left(L_{m d}-L_{m q}\right) i_{o d} i_{o q}\right]
$$

From equation (24), the q-axis magnetic current $i_{o q}$ can be expressed as a function of electromagnetic torque $T_{e}$ and the d-axis magnetic current $i_{o d}$.

$$
i_{o q}=T_{e} / 1.5 n_{p}\left[\psi_{f}+\left(L_{m d}-L_{m q}\right) i_{o d}\right]
$$

Substituting equation (25) into equation (23), the controllable part of loss affected by PMSM operation condition can be further simplified as :

$$
P_{\text {loss_PMSM }}=f\left(i_{o d}, \omega_{r}, T_{e} / 1.5 n_{p}\left[\psi_{f}+\left(L_{m d}-L_{m q}\right) i_{o d}\right]\right)=f\left(i_{o d}, \omega_{r}, T_{e}\right)
$$

Equation (26) shows that the controllable part of loss affected by PMSM operation condition can be expressed as a function of the rotational speed $\omega_{r}$, the d-axis magnetic current $i_{\text {od }}$ and the electromagnetic torque $T_{e}$. Therefore for a given toque demand at a given speed, there exists an optimal flux-weakening d-axis magnetic current which can yield the maximum efficiency. The optimal d-axis magnetic current $i_{o d}{ }^{*}$ can be obtained from equation (26) as :

$$
\left.\left(\partial P_{\text {loss_ } P M S M} / \partial i_{o d}\right)\right|_{i_{o d}=i_{o d}^{*}} ^{\omega_{r}=c o n s t, T_{e}=\text { const }}=0
$$

From equation (27) the loss optimization control strategy can optimize the stator copper loss and stator iron loss together, and decrease the motor loss in the whole operation range of EVs. However, the optimal current $i_{o d}{ }^{*}$ is limited by two aspects. The first aspect is that the optimal current in the d-axis must be less than the maximum flux-wakening current which will cause irreversible magnet demagnetization :

$$
\left|i_{\text {od }}^{*}\right| \leq\left|i_{d_{-} \text {permenent_magnet }}\right|
$$

where $i_{d_{-} \text {permanet_magnent }}$ is the maximum flux-wakening current of permanent magnet in the PMSM.

The second aspect is that the optimal d-axis current is limited by the maximum inverter current :

$$
i_{d}^{2}+i_{q}^{2} \leq I_{s_{-} \max }^{2}
$$

where $I_{s_{-} \max }$ is the maximum current of inverter.

For the case of surface-mount PM machines (SPMSMs), the non-salient rotor structure makes the stator self-inductance in the d-axis equal to that in the q-axis. Therefore, the optimal operation point of the SPMSM by the proposed loss optimization control strategy can be calculated as : 


$$
i_{o d}=-n_{p}^{2} \omega_{r}^{2} L_{s} \psi_{f}\left(R_{s}+R_{c}\right) / n_{p}^{2} \omega_{r}^{2} L_{s}^{2}\left(R_{s}+R_{c}\right)+R_{s} R_{c}^{2}
$$

where $L_{s}$ is the stator inductance of SPMSM,

$$
L_{s}=L_{m d}=L_{m q}
$$

\subsection{Optimization on the loss affected by inverter state}

From the previously discussed equation (27) it was shown that there is an optimal current which minimizes both the copper and iron losses. By applying the aforesaid optimal current to the PMSM drive system, the loss affected by the inverter state is then only a function of the PWM frequency:

$$
\begin{aligned}
P_{\text {loss_inverter }}=12 f_{s w} U_{d c} \cdot\left[\begin{array}{l}
\left(c_{o n}+c_{o f f}+c_{r e c}\right) I_{0}^{2} / 4 \\
+\left(b_{o n}+b_{o f f}+b_{r e c}\right) I_{0} / \pi \\
+\left(a_{o n}+a_{o f f}+a_{r e c}\right) / 2
\end{array}\right] / U_{d c_{-} \text {test }} \\
=f\left(f_{s w}, U_{d c}, I_{0}\right)
\end{aligned}
$$

Hence the inverter losses can be decreased by reducing the switching frequency of the PWM signal. However as the motor is fed by a PWM inverter there are several harmonic currents in the stator windings, the magnitude of which will increase with lowering the switching frequency. For the application in hand, being a direct-drive system, the motors are directly connected to the load, therefore the large harmonic stator current affects the overall drive stability. It is thus critical to obtain the harmonic content with different PWM switching frequencies.

Determination of the harmonic frequency components of a PWM switched inverter output is quite complex and is often done by using a fast Fourier transform (FFT) analysis of a simulated time-varying switched waveform. This approach reduces the mathematical effort, but it still requires considerable computing capacity and leaves uncertainty as to whether a subtle simulation round-off or error may have affected the results obtained. In contrast, an analytical solution using double Fourier integral analysis can exactly identify the harmonic components of a PWM waveform, and is thus used within the loss optimization control strategy In double Fourier integral analysis theory, the PWM output voltage of the inverter can be obtained by two time variables, $x(t)$ and $y(t)$, where $x(t)$ is the carrier signal and $\mathrm{y}(\mathrm{t})$ is the fundamental (sinusoid) signal.

$$
x(t)=\omega_{c} t+\theta_{c}
$$

where $\omega_{c}$ is the carrier angular frequency and $\theta_{c}$ is the arbitrary phase offset angle for the carrier waveform.

$$
y(t)=\omega_{0} t+\theta_{0}
$$

where $\omega_{0}$ is the fundamental angular frequency and $\theta_{0}$ is the arbitrary phase offset angle for the fundamental waveform.

The output voltage of the inverter leg can be described as :

$$
a_{n}(t)=f(x(t), y(t))= \begin{cases}2 U_{d c} & y(t)>x(t) \\ 0 & y(t) \leq x(t)\end{cases}
$$


where $2 \mathrm{U}_{\mathrm{dc}}$ is the DC voltage as shown in Fig.2. The output voltage of the inverter leg is defined with respect to the negative DC bus rather than to the midpoint of the DC bus, in order to simplify the mathematics of the Fourier solution.

With double Fourier integral analysis theory [40,41], the time-varying function $\mathrm{f}(\mathrm{x}(\mathrm{t}), \mathrm{y}(\mathrm{t}))$ can be expressed as a summation of the harmonic components :

$$
\begin{aligned}
f(x, y)= & A_{00} / 2+\sum_{n=1}^{\infty}\left\{A_{0 n} \cos \left[n\left(\omega_{0} t+\theta_{0}\right)\right]+B_{0 n} \sin \left[n\left(\omega_{0} t+\theta_{0}\right)\right]\right\} \\
& +\sum_{m=1}^{\infty}\left\{A_{m 0} \cos \left[m\left(\omega_{c} t+\theta_{c}\right)\right]+B_{m 0} \sin \left[m\left(\omega_{c} t+\theta_{c}\right)\right]\right\} \\
& +\sum_{m=1}^{\infty} \sum_{\substack{n=-\infty \\
(n \neq 0)}}^{\infty}\left\{\begin{array}{l}
A_{m n} \cos \left[m\left(\omega_{c} t+\theta_{c}\right)+n\left(\omega_{0} t+\theta_{0}\right)\right] \\
+B_{m n} \sin \left[m\left(\omega_{c} t+\theta_{c}\right)+n\left(\omega_{0} t+\theta_{0}\right)\right]
\end{array}\right\}
\end{aligned}
$$

where $A_{00}$ is the DC offset; $A_{0 n}$ and $B_{0 n}$ are the fundamental component and base-band harmonics; $A_{m 0}$ and $B_{m 0}$ are the carrier harmonics; $A_{m n}$ and $B_{m n}$ are side-band harmonics.

Based on the double Fourier integral analysis, the fundamental component and harmonics of the inverter leg output can then be calculated as

$$
A_{m n}+j B_{m n}=\int_{-\pi}^{\pi} \int_{-\frac{\pi}{2}(1+M \cos y)}^{\frac{\pi}{2}(1+M \cos y)} 2 U_{d c} \exp [j(m x+n y)] d x d y / 2 \pi^{2}
$$

From Table 1, the phase leg reference voltage for SVPWM can be obtained as described in Table 2.

Table 2. Phase reference voltage for SVPWM.

\begin{tabular}{cccc}
\hline $\boldsymbol{\omega}_{\mathbf{0}} \mathbf{t}=\boldsymbol{\theta}_{\mathbf{0}}$ & A Phase Leg & B Phase Leg & C Phase Leg \\
\hline $0 \leq \theta_{0}<\pi / 3$ & $\sqrt{3} M U_{d c} \cos \left(\theta_{0}+\pi / 6\right) / 2$ & $\sqrt{3} M U_{d c} \cos \left(\theta_{0}-5 \pi / 6\right) / 2$ & $3 M U_{d c} \cos \left(\theta_{0}+2 \pi / 3\right) / 2$ \\
$\pi / 3 \leq \theta_{0}<2 \pi / 3$ & $\left(3 M U_{d c} \cos \theta_{0}\right) / 2$ & $\left(\sqrt{3} M U_{d c} \cos \theta_{0}\right) / 2$ & $-\left(\sqrt{3} M U_{d c} \cos \theta_{0}\right) / 2$ \\
$2 \pi / 3 \leq \theta_{0}<\pi$ & $\sqrt{3} M U_{d c} \cos \left(\theta_{0}-\pi / 6\right) / 2$ & $\frac{3}{2} M U_{d c} \cos \left(\theta_{0}-\frac{2}{3} \pi\right)$ & $\sqrt{3} M U_{d c} \cos \left(\theta_{0}+5 \pi / 6\right) / 2$ \\
$\pi \leq \theta_{0}<4 \pi / 3$ & $\sqrt{3} M U_{d c} \cos \left(\theta_{0}+\pi / 6\right) / 2$ & $\sqrt{3} M U_{d c} \cos \left(\theta_{0}-5 \pi / 6\right) / 2$ & $3 M U_{d c} \cos \left(\theta_{0}+2 \pi / 3\right) / 2$ \\
$4 \pi / 3 \leq \theta_{0}<5 \pi / 3$ & $\left(3 M U_{d c} \cos \theta_{0}\right) / 2$ & $\left(\sqrt{3} M U_{d c} \cos \theta_{0}\right) / 2$ & $-\left(\sqrt{3} M U_{d c} \cos \theta_{0}\right) / 2$ \\
$5 \pi / 3 \leq \theta_{0}<2 \pi$ & $\sqrt{3} M U_{d c} \cos \left(\theta_{0}-\pi / 6\right) / 2$ & $3 M U_{d c} \cos \left(\theta_{0}-2 \pi / 3\right) / 2$ & $\sqrt{3} M U_{d c} \cos \left(\theta_{0}+5 \pi / 6\right) / 2$ \\
\hline
\end{tabular}

Table 2 shows that the phase reference signal for SVPWM is not a continuous function, but is made up of six segments, each spanning $60^{\circ}$ for a complete fundamental cycle :

$$
A_{m n}+j B_{m n}=\sum_{i=1}^{6} \int_{y_{1}(i)}^{y_{2}(i)} \int_{x_{1}(i)}^{x_{2}(i)} 2 U_{d c} \exp [j(m x+n y)] d x d y / 2 \pi^{2}
$$

The outer and inner integral limits of equation (38) are defined in Table 3. From equation (35), the harmonic components of the output voltage in A phase leg of inverter can be obtained as : 


$$
\begin{aligned}
u_{a z}(t)= & A_{00} / 2+\sum_{n=1}^{\infty}\left[A_{0 n} \cos \left(n \omega_{0} t\right)+B_{0 n} \sin \left(n \omega_{0} t\right)\right] \\
& +\sum_{m=1}^{\infty}\left\{A_{m 0} \cos \left[m\left(\omega_{c} t+\theta_{c}\right)\right]+B_{m 0} \sin \left[m\left(\omega_{c} t+\theta_{c}\right)\right]\right\} \\
& +\sum_{m=1}^{\infty} \sum_{\substack{n=-\infty \\
(n \neq 0)}}^{\infty}\left\{A_{m n} \cos \left[m\left(\omega_{c} t+\theta_{c}\right)+n \omega_{0} t\right]+B_{m n} \sin \left[m\left(\omega_{c} t+\theta_{c}\right)+n \omega_{0} t\right]\right\}
\end{aligned}
$$

Table 3. Outer and inner integral limits for SVPWM.

\begin{tabular}{ccccc}
\hline $\boldsymbol{i}$ & $\boldsymbol{y}_{\mathbf{1}}(\boldsymbol{i})$ & $\boldsymbol{y}_{\mathbf{2}}(\boldsymbol{i})$ & $\boldsymbol{x}_{\mathbf{1}}(\boldsymbol{i})$ & $\boldsymbol{x}_{\mathbf{2}}(\boldsymbol{i})$ \\
\hline 1 & $2 \pi / 3$ & $\pi$ & $-\pi[1+\sqrt{3} M \cos (y+\pi / 6) / 2] / 2$ & $\pi[1+\sqrt{3} M \cos (y+\pi / 6) / 2] / 2$ \\
2 & $\pi / 3$ & $2 \pi / 3$ & $-\pi(1+3 M \cos y / 2) / 2$ & $\pi(1+3 M \cos y / 2) / 2$ \\
3 & 0 & $\pi / 3$ & $-\pi[1+\sqrt{3} M \cos (y-\pi / 6) / 2] / 2$ & $\pi[1+\sqrt{3} M \cos (y-\pi / 6) / 2] / 2$ \\
4 & $-\pi / 3$ & 0 & $-\pi[1+\sqrt{3} M \cos (y+\pi / 6) / 2] / 2$ & $\pi[1+\sqrt{3} M \cos (y+\pi / 6) / 2] / 2$ \\
5 & $-2 \pi / 3$ & $-\pi / 3$ & $-\pi(1+3 M \cos y / 2) / 2$ & $\pi(1+3 M \cos y / 2) / 2$ \\
6 & $-\pi$ & $-2 \pi / 3$ & $-\pi[1+\sqrt{3} M \cos (y-\pi / 6) / 2] / 2$ & $\pi[1+\sqrt{3} M \cos (y-\pi / 6) / 2] / 2$ \\
\hline
\end{tabular}

The harmonic coefficients can be expressed as :

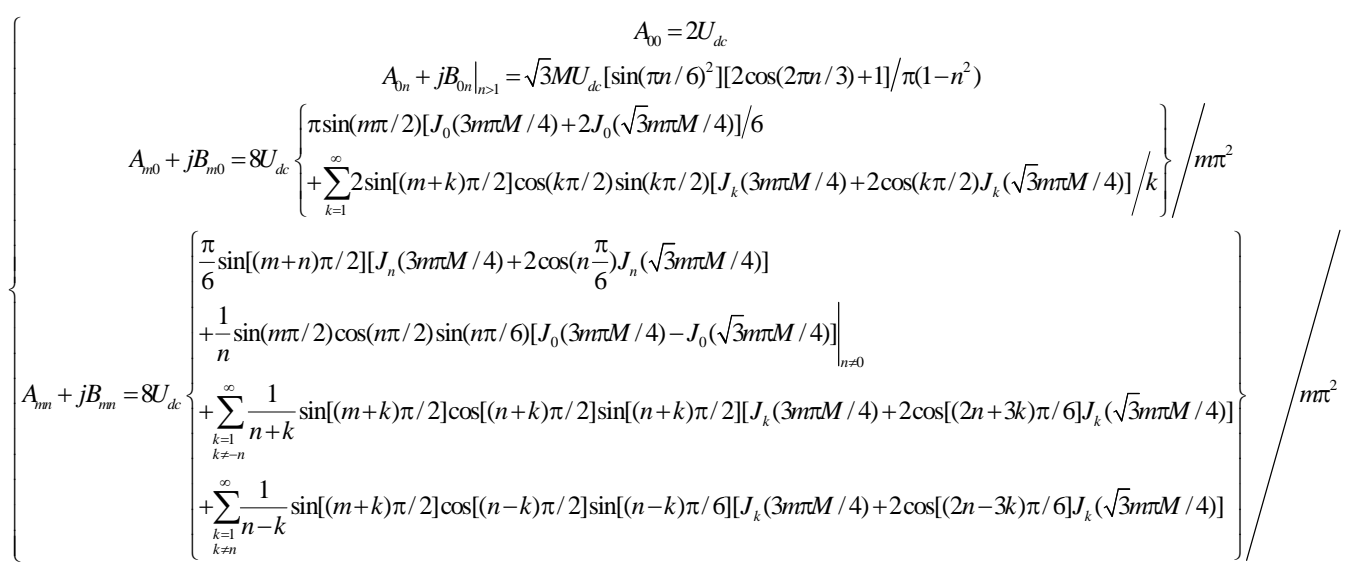

where the constant term $A_{00}$ is caused by the output voltage definition with respect to the negative DC bus as previously discussed. The harmonic voltage in equation (39) is also calculated with respect to the negative DC bus, hence the harmonic voltage with respect to the neutral point can be obtained as

$$
\dot{u}_{a n_{n m}}=\dot{u}_{a z_{n m}}-\left(\dot{u}_{a z_{n m}}+\dot{u}_{b z_{n m}}+\dot{u}_{c z_{n m}}\right) / 3
$$

where $\dot{u}_{a z_{n m}}, \dot{u}_{b z_{n m}}$ and $\dot{u}_{b z_{n m}}$ are the harmonic voltages with respect to the negative DC bus in the $n$-th fundamental signal and the $m$-th carrier signal. In addition, $\dot{u}_{a n_{n m}}$ is the harmonic voltage with respect to the load neutral point in the $n$th fundamental signal and the $m$-th carrier signal.

Based on equation (41), the stator harmonic current can be obtained as

$$
I_{s_{n n}}=\left|\dot{u}_{a n_{n n}} /\left(R_{s}+j \omega_{m n} L_{s}\right)\right|
$$

From equation (42), the loss minimization control can acquire the optimal PWM frequency $f_{P W M}{ }^{*}$ by the following : 


$$
\left(\sum_{m=1}^{\infty} \sum_{\substack{n=-\infty \\ n \neq 0}}^{\infty} i_{A_{m m}}+\sum_{\substack{n=2 \\(m=0)}}^{\infty} i_{A_{m n}}\right) /\left.i_{A_{01}}\right|_{f_{P M M}=f_{P Y M M}^{*}} \leq T H D_{\max }
$$

where $T H D_{\max }$ is the maximum motor current $T H D$ permissible for each EV operational condition in order to keep the system stable.

Hence by adjusting the flux-weakening current $i_{o d}$ to the optimum $i_{o d}{ }^{*}$ and the PWM frequency $f_{P W M}$ to the optimal frequency $f_{P W M}{ }^{*}$, the proposed PMSM control strategy can achieve lower overall losses in the whole EV operation range compared to traditional control strategies, while ensuring drive stability. The structure diagram of the loss minimization control system is shown in Fig.6.

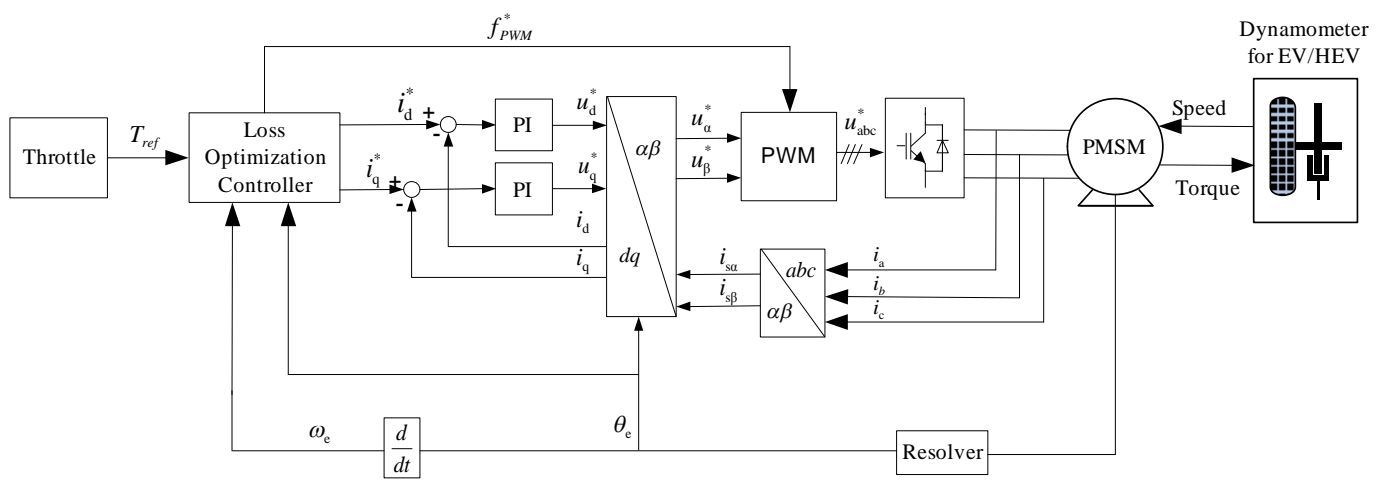

Fig.6. Proposed PMSM direct drive system.

\section{Experiment Study}

In order to verify the effectiveness of the proposed control strategy with respect to conventional control, an experimental platform is designed and implemented as shown in Fig.7. A flowchart describing the steps within the experimental method is shown in Fig.8.

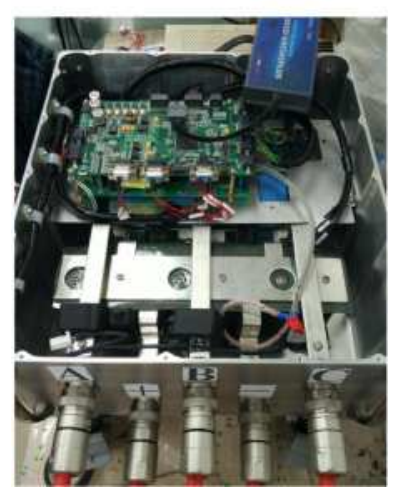

(a)

(b) 


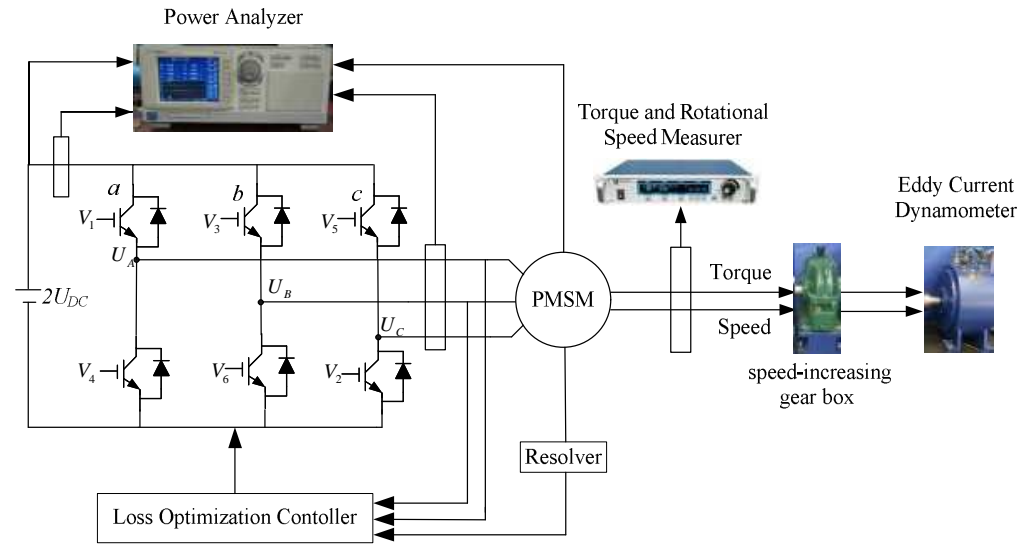

(c)

Fig.7. Experimental platform of PMSM system. (a) SiC- MOSFETs based converter; (b) Physical prototype experimental platform; (c) The structure schematic diagram of the experimental platform.

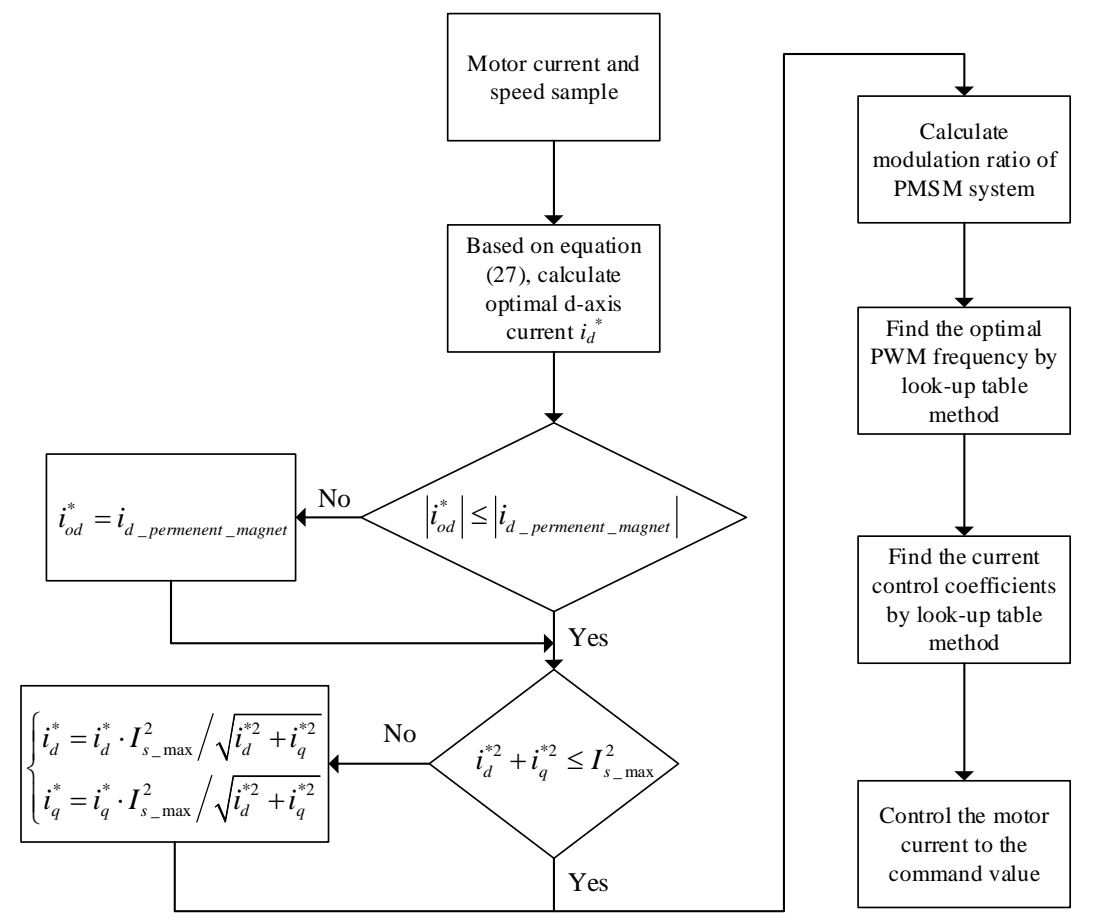

Fig.8. Flowchart of the proposed method in the experimental PMSM.

The proposed control strategy calculates the optimal d-axis current $i_{d}{ }^{*}$ by equation (27), and limits the optimal d-axis current $i_{d}{ }^{*}$ by equation (28) and (29). The optimal PWM frequency is then calculated off-line by equation (43). The control method applies the optimal PWM frequency and current control coefficients by means of a hysteresis look-up table. In order to maintain the stability of the experimental system, the command d-axis current is gradually reduced to the optimal d-axis current.

The three-phase half-bridge inverter utilized is based on the SiC-MOSFET modules (CAS300M12BM2) which can obtain lower switching losses compared to Si-IGBTs. The inverter is controlled by the TMS320F28335 which implements both the traditional MTPA control strategy and the proposed loss 
minimization control strategy on the PMSM direct drive system. The motor used within the experimental setup is a $30 \mathrm{~kW}$ outer rotor surface PMSM, the parameters of which are listed in Table 4.

Table 4. Model parameters of PMSM.

\begin{tabular}{cc}
\hline Parameter & Value \\
\hline Rate power & $30 \mathrm{~kW}$ \\
Rate speed & $360 \mathrm{rpm}$ \\
Poles & 22 \\
Slots & 24 \\
Phase resistance & $0.06 \Omega$ \\
Phase inductance & $3.18 \mathrm{mH}$ \\
Flux linkage & $0.623 \mathrm{~Wb}$ \\
DC link range & $360-420 \mathrm{~V}$ \\
\hline
\end{tabular}

Based on experimentation, the module switch-on voltage is chosen as $15 \mathrm{~V}$, while the switch-off voltage is designed as $-5 \mathrm{~V}$. The fitting coefficients of CAS 300M12BM2 are listed in Table 5.

Table 5. Fitting coefficients of SiC-MOSFET modules.

\begin{tabular}{lc}
\hline \multicolumn{1}{c}{ Parameter } & Value \\
\hline Fitted coefficient of conduction characteristics $a_{c}$ & $4.505 \times 10^{-6}$ \\
Fitted coefficient of conduction characteristics $b_{c}$ & 0.005021 \\
Fitted coefficient of conduction characteristics $c_{c}$ & 0.04258 \\
Fitted coefficient of conduction characteristics $a_{f}$ & $-3.3 \times 10^{-6}$ \\
Fitted coefficient of conduction characteristics $b_{f}$ & 0.004911 \\
Fitted coefficient of conduction characteristics $c_{f}$ & 0.5673 \\
Fitted coefficient of switch characteristics $a_{o n}$ & $4.141 \times 10^{-12}$ \\
Fitted coefficient of switch characteristics $b_{\text {on }}$ & $1.418 \times 10^{-8}$ \\
Fitted coefficient of switch characteristics $c_{o n}$ & $1.361 \times 10^{-6}$ \\
Fitted coefficient of switch characteristics $a_{\text {off }}$ & $3.48 \times 10^{-11}$ \\
Fitted coefficient of switch characteristics $b_{\text {off }}$ & $8.972 \times 10^{-9}$ \\
Fitted coefficient of switch characteristics $c_{o f f}$ & $1.083 \times 10^{-10}$ \\
\hline
\end{tabular}

A $120 \mathrm{~kW}, 3000 \mathrm{rpm}$ eddy current dynamometer serves as the mechanical load. The speed-increasing gear box is used to increase the maximum rotational speed of the PMSM to the rated speed of the eddy current dynamometer. As a surface PM machine is used within the experimental setup, the inductance in the $\mathrm{d}$-axis is equal to that in the q-axis, hence the MTPA control strategy uses $i_{d}=0$. The experimental results of the selected PMSM direct drive system under MTPA control are shown in Table 6 and Table 7. Table 6 shows the experimental results of SiC-MOSFET based PMSM drive system corresponding to different powers at rated speed, while Table 7 shows the experimental results corresponding to different speeds at rated torque. 
Table 6. Experimental results at rated speed under MTPA control.

\begin{tabular}{cccccccc}
\hline $\begin{array}{c}\text { Output } \\
\text { torque } \\
(\mathrm{N} \cdot \mathrm{m})\end{array}$ & $\begin{array}{c}\text { Motor } \\
\text { current }\end{array}$ & $\begin{array}{c}\text { Mechanical } \\
\text { power }(\mathrm{kW})\end{array}$ & $\begin{array}{c}\text { Motor } \\
\text { input } \\
\text { power } \\
(\mathrm{kW})\end{array}$ & $\begin{array}{c}\text { System } \\
\text { input } \\
\text { power } \\
(\mathrm{kW})\end{array}$ & $\begin{array}{c}\text { Motor } \\
\text { efficiency }\end{array}$ & $\begin{array}{c}\text { Inverter } \\
\text { efficiency }\end{array}$ & $\begin{array}{c}\text { System } \\
\text { efficiency }\end{array}$ \\
\hline 725 & 93.1 & 27.33 & 29.66 & 30.13 & $92.05 \%$ & $98.55 \%$ & $90.72 \%$ \\
600 & 76.3 & 22.62 & 24.57 & 24.81 & $92.08 \%$ & $99.02 \%$ & $91.17 \%$ \\
500 & 63.1 & 18.85 & 20.52 & 20.79 & $91.87 \%$ & $98.69 \%$ & $90.67 \%$ \\
400 & 50.5 & 15.08 & 16.52 & 16.85 & $91.28 \%$ & $98.02 \%$ & $89.47 \%$ \\
300 & 38.3 & 11.31 & 12.57 & 12.91 & $89.95 \%$ & $97.37 \%$ & $87.58 \%$ \\
200 & 26.3 & 7.54 & 8.68 & 9.11 & $86.89 \%$ & $95.25 \%$ & $82.76 \%$ \\
100 & 14.7 & 3.77 & 4.84 & 5.37 & $77.90 \%$ & $90.09 \%$ & $70.18 \%$ \\
\hline
\end{tabular}

Table 7. Experimental results at rated torque under MTPA control.

\begin{tabular}{cccccccc}
\hline $\begin{array}{c}\text { Speed of } \\
\text { PMSM } \\
(\mathrm{rpm})\end{array}$ & $\begin{array}{c}\text { Motor } \\
\text { current }\end{array}$ & $\begin{array}{c}\text { Mechanical } \\
\text { power }(\mathrm{kW})\end{array}$ & $\begin{array}{c}\text { Motor } \\
\text { input } \\
\text { power } \\
(\mathrm{kW})\end{array}$ & $\begin{array}{c}\text { System } \\
\text { input } \\
\text { power } \\
(\mathrm{kW})\end{array}$ & $\begin{array}{c}\text { Motor } \\
\text { efficiency }\end{array}$ & $\begin{array}{c}\text { Inverter } \\
\text { efficiency }\end{array}$ & $\begin{array}{c}\text { System } \\
\text { efficiency }\end{array}$ \\
\hline 360 & 93.1 & 27.33 & 29.66 & 30.13 & $92.05 \%$ & $98.55 \%$ & $90.72 \%$ \\
300 & 92.9 & 22.77 & 24.77 & 25.77 & $91.92 \%$ & $98.43 \%$ & $90.47 \%$ \\
250 & 92.7 & 18.98 & 20.73 & 21.34 & $91.55 \%$ & $97.13 \%$ & $88.92 \%$ \\
200 & 92.3 & 15.18 & 16.73 & 17.67 & $90.76 \%$ & $94.69 \%$ & $85.94 \%$ \\
150 & 91.9 & 11.39 & 12.78 & 13.86 & $89.15 \%$ & $92.16 \%$ & $82.16 \%$ \\
100 & 91.4 & 7.59 & 8.86 & 10.12 & $85.65 \%$ & $87.60 \%$ & $75.02 \%$ \\
50 & 90.8 & 3.80 & 5.00 & 6.47 & $75.93 \%$ & $77.30 \%$ & $58.69 \%$ \\
\hline
\end{tabular}

The loss optimization control strategy carefully optimizes the stator current and PWM frequency at each working point and can achieve higher system efficiency across the whole operation range. Table 8 and Table 9 show the experimental results for the loss optimization control strategy.

Table 8. Experimental results at rated speed for the proposed loss optimization control.

\begin{tabular}{cccccccc}
\hline $\begin{array}{c}\text { Output } \\
\text { torque }\end{array}$ & $\begin{array}{c}\text { Motor } \\
\text { current }\end{array}$ & $\begin{array}{c}\text { Mechanical } \\
\text { power }(\mathrm{kW})\end{array}$ & $\begin{array}{c}\text { Motor } \\
\text { input } \\
\text { power } \\
(\mathrm{kW})\end{array}$ & $\begin{array}{c}\text { System } \\
\text { input } \\
\text { power } \\
(\mathrm{kW})\end{array}$ & $\begin{array}{c}\text { Motor } \\
\text { efficiency }\end{array}$ & $\begin{array}{c}\text { Inverter } \\
\text { efficiency }\end{array}$ & $\begin{array}{c}\text { System } \\
\text { efficiency }\end{array}$ \\
\hline 725 & 93.5 & 27.33 & 29.66 & 30.11 & $92.13 \%$ & $98.51 \%$ & $90.76 \%$ \\
600 & 76.7 & 22.62 & 24.55 & 24.80 & $92.18 \%$ & $98.99 \%$ & $91.25 \%$ \\
500 & 63.7 & 18.85 & 20.50 & 20.78 & $91.97 \%$ & $98.66 \%$ & $90.73 \%$ \\
400 & 51.2 & 15.08 & 16.50 & 16.84 & $91.42 \%$ & $97.27 \%$ & $89.56 \%$ \\
300 & 39.2 & 11.31 & 12.55 & 12.90 & $90.13 \%$ & $97.30 \%$ & $87.70 \%$ \\
200 & 27.6 & 7.54 & 8.65 & 9.10 & $87.17 \%$ & $95.12 \%$ & $82.92 \%$ \\
100 & 16.8 & 3.77 & 4.77 & 5.32 & $78.42 \%$ & $89.80 \%$ & $70.43 \%$ \\
\hline
\end{tabular}


Table 9. Experimental results at rated torque for the proposed loss optimization control.

\begin{tabular}{cccccccc}
\hline $\begin{array}{c}\text { Speed of } \\
\text { PMSM } \\
(\mathrm{rpm})\end{array}$ & $\begin{array}{c}\text { Motor } \\
\text { current } \\
(\mathrm{A})\end{array}$ & $\begin{array}{c}\text { Mechanical } \\
\text { power }(\mathrm{kW})\end{array}$ & $\begin{array}{c}\text { Motor } \\
\text { input } \\
\text { power } \\
(\mathrm{kW})\end{array}$ & $\begin{array}{c}\text { System } \\
\text { input } \\
\text { power } \\
(\mathrm{kW})\end{array}$ & $\begin{array}{c}\text { Motor } \\
\text { efficiency }\end{array}$ & $\begin{array}{c}\text { Inverter } \\
\text { efficiency }\end{array}$ & $\begin{array}{c}\text { System } \\
\text { efficiency }\end{array}$ \\
\hline 360 & 93.5 & 27.33 & 29.66 & 30.11 & $92.13 \%$ & $98.51 \%$ & $90.76 \%$ \\
300 & 93.1 & 22.77 & 24.75 & 25.12 & $91.98 \%$ & $98.54 \%$ & $90.63 \%$ \\
250 & 92.8 & 18.98 & 20.71 & 21.25 & $91.59 \%$ & $97.44 \%$ & $89.25 \%$ \\
200 & 92.3 & 15.18 & 16.74 & 17.53 & $90.78 \%$ & $95.52 \%$ & $86.72 \%$ \\
150 & 91.9 & 11.39 & 12.78 & 13.64 & $89.15 \%$ & $93.75 \%$ & $83.58 \%$ \\
100 & 91.4 & 7.59 & 8.87 & 9.79 & $85.64 \%$ & $90.61 \%$ & $77.60 \%$ \\
50 & 90.8 & 3.80 & 5.01 & 6.01 & $75.90 \%$ & $83.34 \%$ & $63.26 \%$ \\
\hline
\end{tabular}

The experimental results from Table 6 to Table 9 verify that the proposed control strategy can increase the system efficiency for all considered cases. Fig.9. compares the motor current for both the implemented control strategies, showing that the difference increases as the motor torque is reduced.

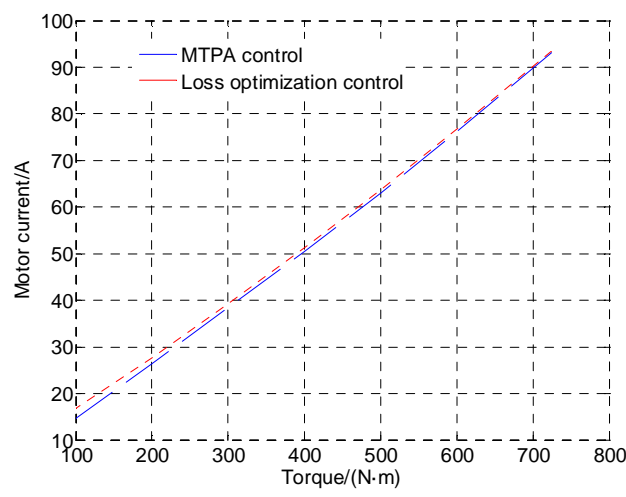

(a)

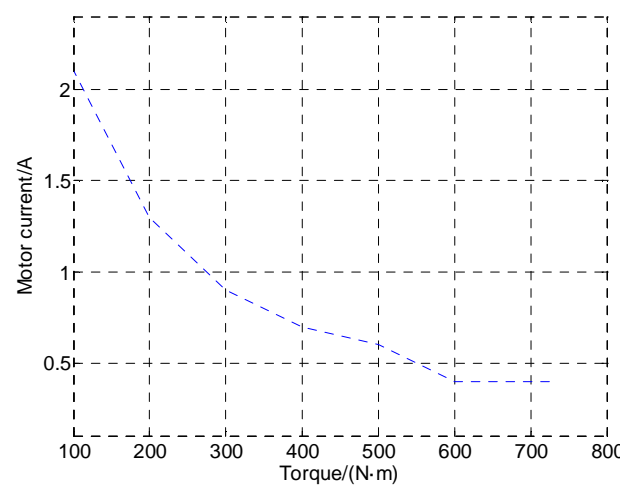

(b)

Fig.9 Motor current with two control strategies in the rated speed. (a) Motor current; (b) Difference of motor current.

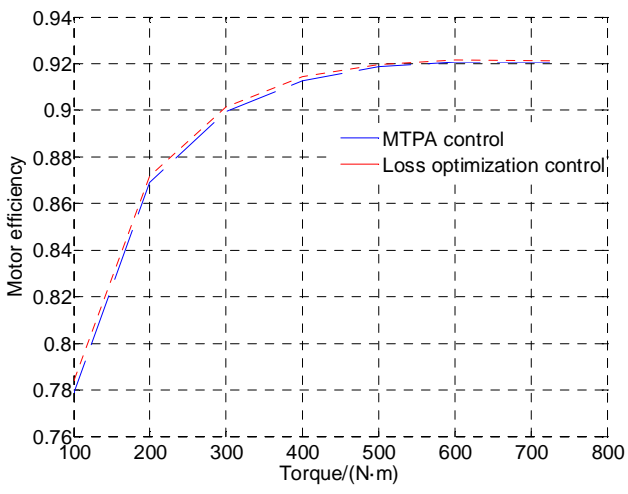

(a)

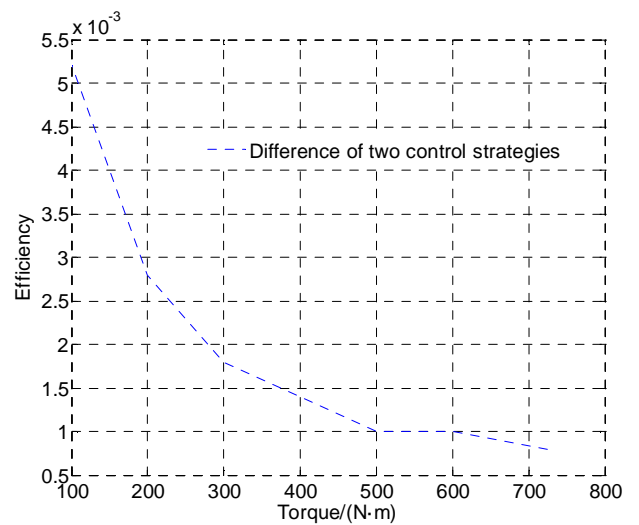

(b)

Fig.10 Motor efficiency with two control strategies in the rated speed. (a) Motor efficiency; (b) Difference of motor efficiency. 
As shown in Fig.10 which compares the motor efficiency at rated speed (360rpm) under different control, the proposed control strategy yields a better motor efficiency improvement entitlement especially when the difference between the iron losses and copper losses is higher (i.e. when the torque is lower), with the maximum improvement of $0.52 \%$ achieved at rated speed for the case of $100 \mathrm{Nm}$.

By the combined optimization of the motor and the SiC-MOSFET converter, the loss optimization control strategy can enhance the system efficiency by up to $0.25 \%$ at rated speed as shown in Fig. 11 .

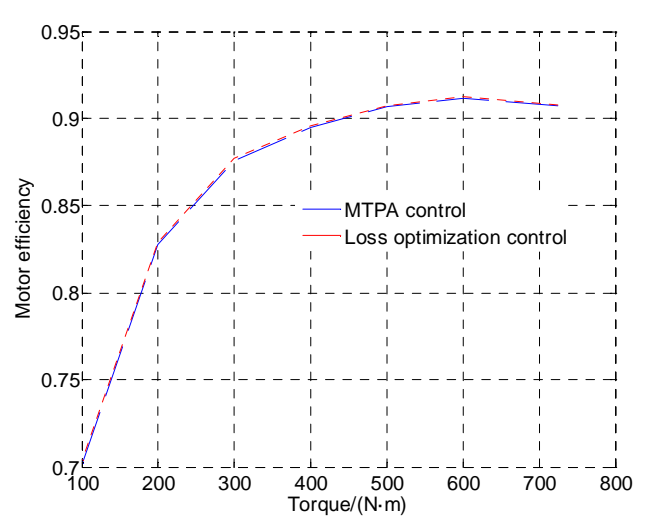

(a)

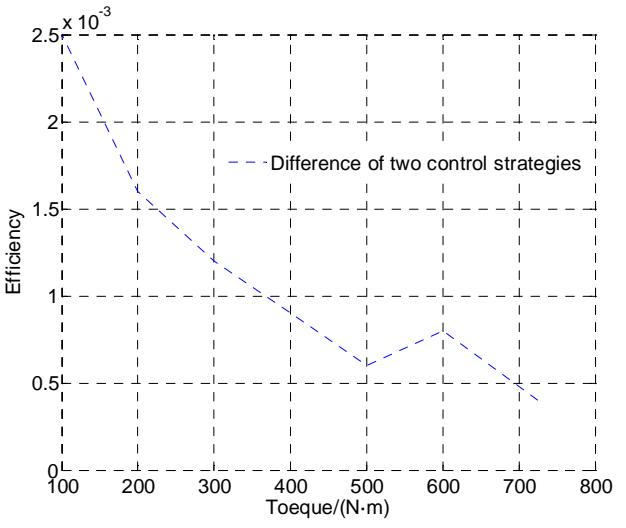

(b)

Fig.11 System efficiency with two control strategies in the rated speed. (a) System efficiency; (b) Difference of system efficiency.

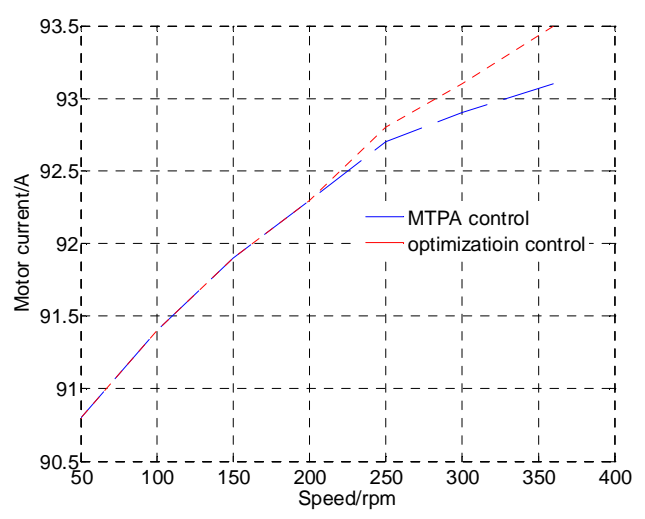

(a)

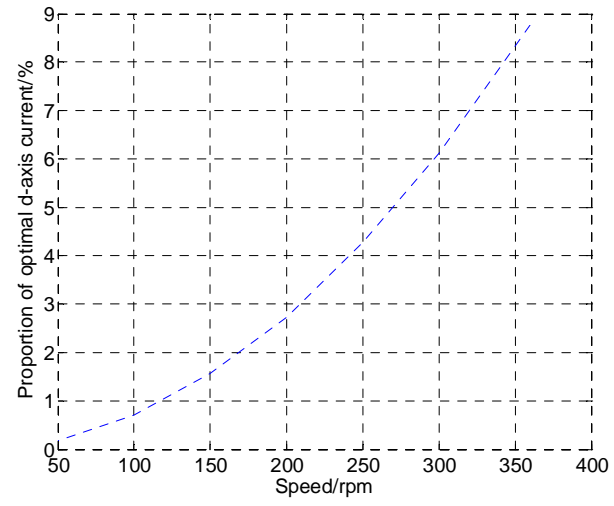

(b)

Fig.12 (a)Difference of motor current between MTPA control and proposed control in the rated torque (b)

Proportion of optimal d-axis current with motor current in the proposed control method

Fig.12 (a) compares the motor current corresponding to the different control methods for different speeds. It is noted that the developed control uses a higher current at high speeds (i.e. higher copper losses), but this is because of an increasing amount of d-axis current, as shown in Fig.12(b) which has the effect of opposing the magnet flux thereby reducing the iron losses, and minimizing the overall machine losses

The difference of inverter efficiency with the two control strategies at the rated torque $(720 \mathrm{Nm})$ is hsown in Fig.13. 


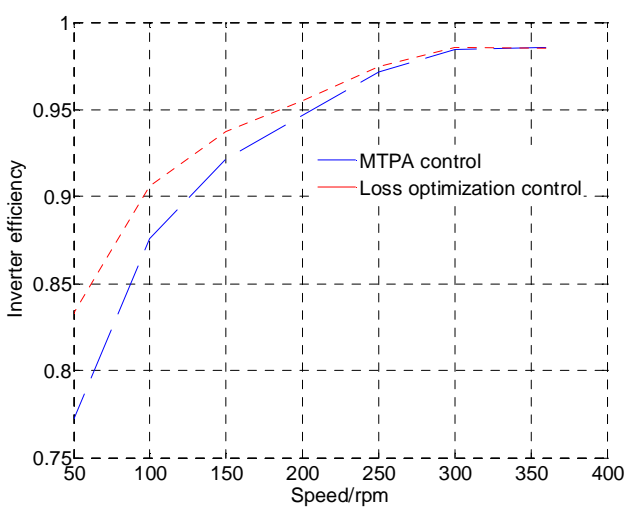

(a)

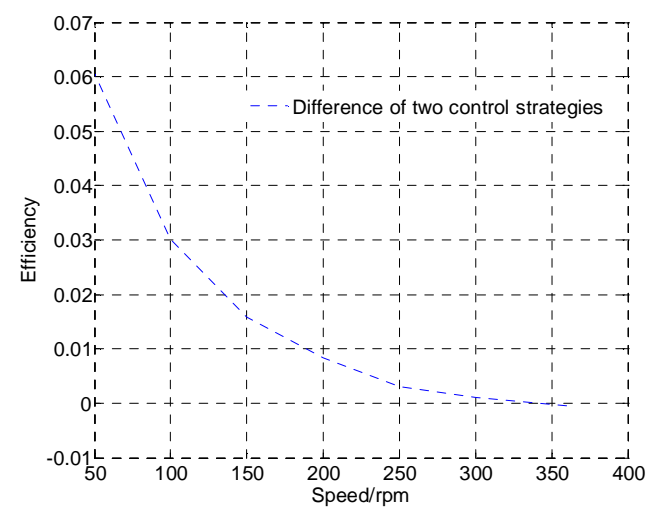

(b)

Fig.13. Inverter efficiency with two control strategies at rated torque. (a) Inverter efficiency; (b) Difference of inverter efficiency.

The loss optimization control can decrease the inverter losses almost the entire speed range of EVs. By using SiC-MOSFETs as the power devices, the switching losses of the inverter are reduced and an inverter efficiency of $98.51 \%$ efficiency is obtained at the high speed end. It is noted that the efficiency of the inverter is reduced when the motor slows down. However by optimizing the stator current and PWM switching frequency, the proposed loss minimization control strategy can improve the inverter efficiency by about $6 \%$ at low speeds. Of note, fig. 13 also shows that the inverter efficiency at 350rpm is lower by the proposed loss optimization control. This is caused by the increased stator current in the d-axis. The control strategy is based on the operation condition of PMSM drive system and at the aforementioned point although the converter efficiency will be slightly worse, this is outweighed by the gains in the overall system efficiency which is shown in Fig.14.

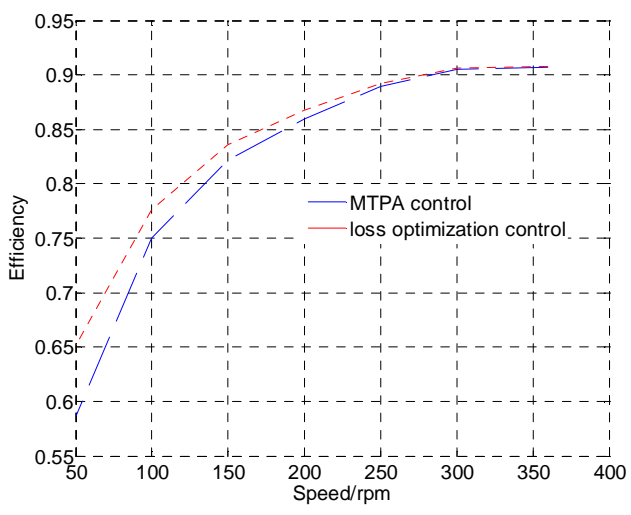

(a)

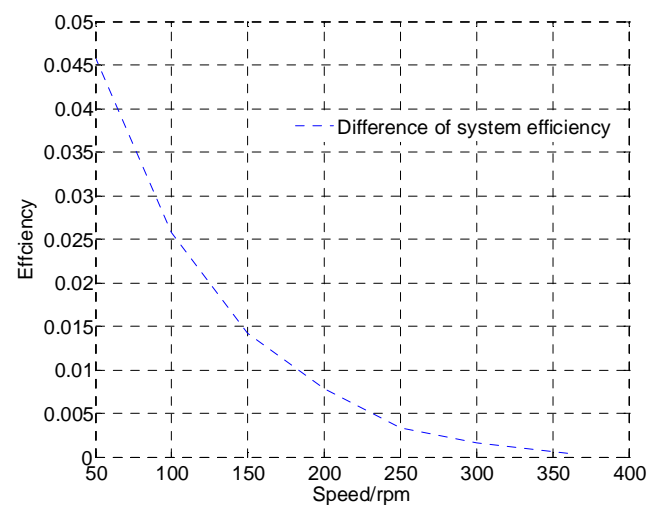

(b)

Fig.14. System efficiency with two control strategies in the rated torque. (a) System efficiency; (b) Difference of system efficiency.

From Fig.14 compared with traditional MTPA control, the loss minimiztion control strategy can reduce the system loss at each working point of EVs. Although the system efficiency of PMSM direct drive system reaches $90.76 \%$ at the rated operation point by traditional MTPA control, the loss optimization control method improves the system efficiency by $4.6 \%$ at low speeds, and thus broadens the high efficiency drive operation area which is very important to EVs. 
As the switching losses in Si-IGBTs are higher than the switching losses in SiC-MOSFETs, it follows that the proposed optimization control method should yield higher efficiency improvement when implemented on a traditional Si-IGBT-based converter. To this end the same motor is tested using a Si-IGBT (FF300R06KE3_BE2) based power converter shown in Fig.15, with the experimental results at rated torque under MTPA and under the developed control method listed in Table 10 and Table 11 respectively.

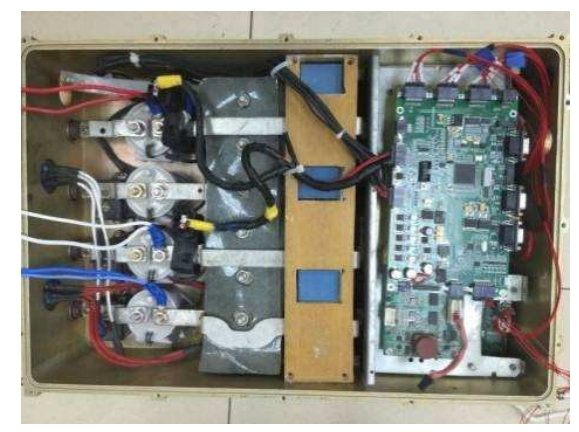

Fig.15 Si-IGBT based power converter for PMSM direct drive system.

Table 10. Experimental results of Si-IGBT based PMSM system at rated torque in the MTPA control.

\begin{tabular}{ccccccc}
\hline $\begin{array}{c}\text { Speed of } \\
\text { PMSM } \\
(\mathrm{rpm})\end{array}$ & $\begin{array}{c}\text { Mechanical } \\
\text { power }(\mathrm{kW})\end{array}$ & $\begin{array}{c}\text { Motor } \\
\text { input } \\
\text { power } \\
(\mathrm{kW})\end{array}$ & $\begin{array}{c}\text { System } \\
\text { input } \\
\text { power } \\
(\mathrm{kW})\end{array}$ & $\begin{array}{c}\text { Motor } \\
\text { efficiency }\end{array}$ & $\begin{array}{c}\text { Inverter } \\
\text { efficiency }\end{array}$ & $\begin{array}{c}\text { System } \\
\text { efficiency }\end{array}$ \\
\hline 360 & 27.33 & 29.9 & 30.93 & $92.05 \%$ & $95.98 \%$ & $88.34 \%$ \\
300 & 22.77 & 24.77 & 26.04 & $91.92 \%$ & $95.11 \%$ & $87.42 \%$ \\
250 & 18.98 & 20.73 & 22.39 & $91.55 \%$ & $92.57 \%$ & $84.74 \%$ \\
200 & 15.18 & 16.73 & 18.38 & $90.76 \%$ & $91.02 \%$ & $82.60 \%$ \\
150 & 11.39 & 12.78 & 14.62 & $89.15 \%$ & $87.43 \%$ & $77.94 \%$ \\
100 & 7.59 & 8.86 & 10.76 & $86.65 \%$ & $82.36 \%$ & $70.54 \%$ \\
50 & 3.80 & 5.00 & 7.29 & $75.93 \%$ & $68.62 \%$ & $52.10 \%$ \\
\hline
\end{tabular}

Table 11. Experimental results of Si-IGBT based PMSM system at rated torque in the proposed loss optimization control.

\begin{tabular}{ccccccc}
\hline $\begin{array}{c}\text { Speed of } \\
\text { PMSM } \\
(\mathrm{rpm})\end{array}$ & $\begin{array}{c}\text { Mechanical } \\
\text { power }(\mathrm{kW})\end{array}$ & $\begin{array}{c}\text { Motor } \\
\text { input } \\
\text { power } \\
(\mathrm{kW})\end{array}$ & $\begin{array}{c}\text { System } \\
\text { input } \\
\text { power } \\
(\mathrm{kW})\end{array}$ & $\begin{array}{c}\text { Motor } \\
\text { efficiency }\end{array}$ & $\begin{array}{c}\text { Inverter } \\
\text { efficiency }\end{array}$ & $\begin{array}{c}\text { System } \\
\text { efficiency }\end{array}$ \\
\hline 360 & 27.33 & 29.66 & 30.91 & $92.13 \%$ & $95.97 \%$ & $88.42 \%$ \\
300 & 22.77 & 24.75 & 25.89 & $91.98 \%$ & $95.59 \%$ & $87.94 \%$ \\
250 & 18.98 & 20.71 & 22.04 & $91.59 \%$ & $93.97 \%$ & $86.11 \%$ \\
200 & 15.18 & 16.74 & 17.89 & $90.78 \%$ & $93.57 \%$ & $84.85 \%$ \\
150 & 11.39 & 12.78 & 13.97 & $89.15 \%$ & $91.48 \%$ & $81.53 \%$ \\
100 & 7.59 & 8.87 & 9.97 & $85.64 \%$ & $88.97 \%$ & $76.13 \%$ \\
50 & 3.80 & 5.01 & 6.09 & $75.90 \%$ & $82.27 \%$ & $62.40 \%$ \\
\hline
\end{tabular}


The proposed loss optimization control strategy can increase the Si-IGBT based inverter efficiency over the whole range of motor speed, and it can obtain a marked efficiency improvement of $14 \%$ at lower speeds as shown in Fig.16.

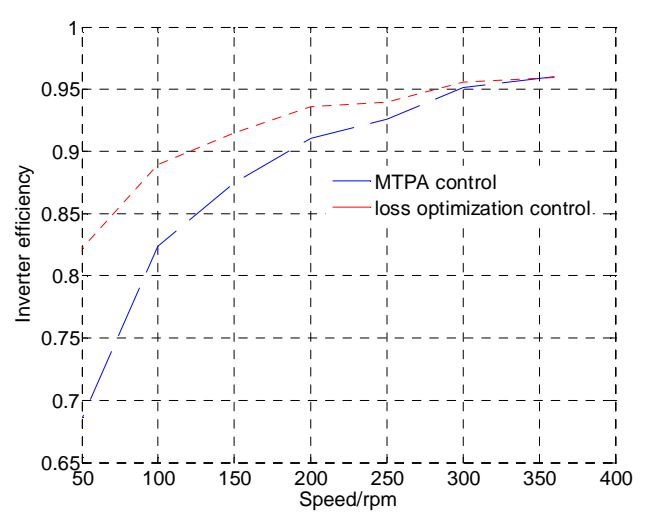

(a)

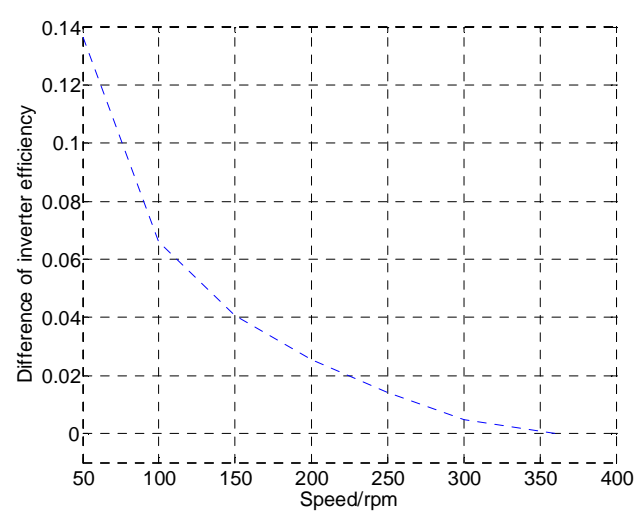

(b)

Fig.16 Si-IGBT based inverter efficiency with two control strategies at the rated torque. (a) Inverter efficiency; (b) Difference of inverter efficiency.

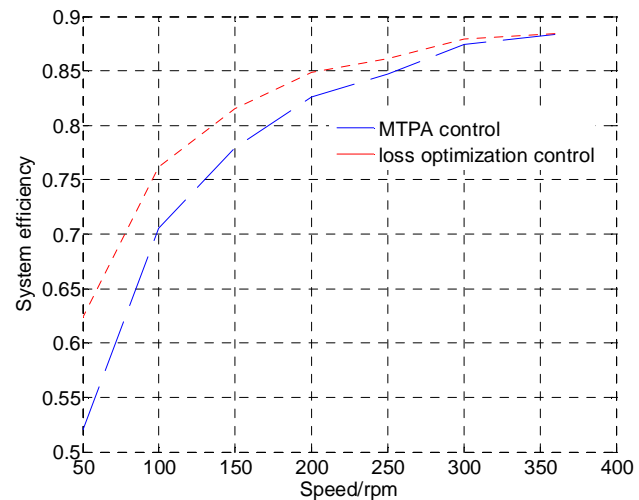

(a)

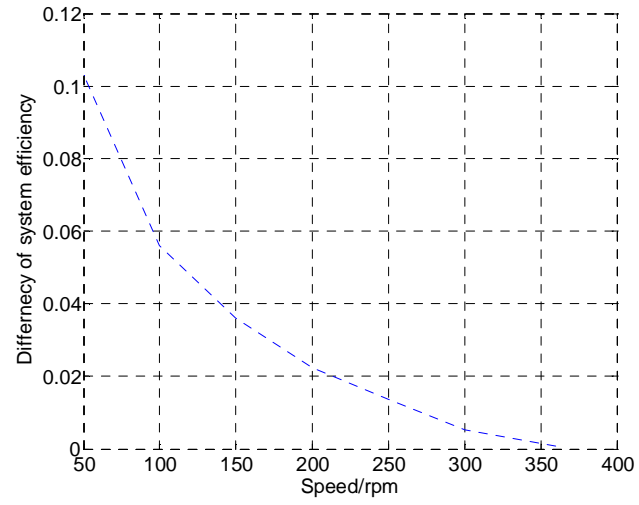

(b)

Fig.17System efficiency with two control strategies at the rated torque. (a) System efficiency; (b) Difference of system efficiency.

The system efficiency at rated torque obtained by the two methods for the case of using a Si-IGBT based inverter is shown in Fig.17, with an improvement of over $10 \%$ at low speeds. Finally, the difference in system efficiency and the overall efficiency improvement between SiC-MOSFET and Si-IGBT based PMSM drives is shown in Fig.18 for the two control methods tested.

Due to the lower switching losses of the power device, the SiC-MOSFET based PMSM system can obtain better system efficiency than the Si-IGBT based PMSM system under both traditional MTPA control and loss minimization control. Comparing Fig.18 (a) and Fig.18 (b) it is show that the proposed control strategy can decrease the influence of power device on the system efficiency, and the entitlement of the proposed control method is more evident at lower speeds. 


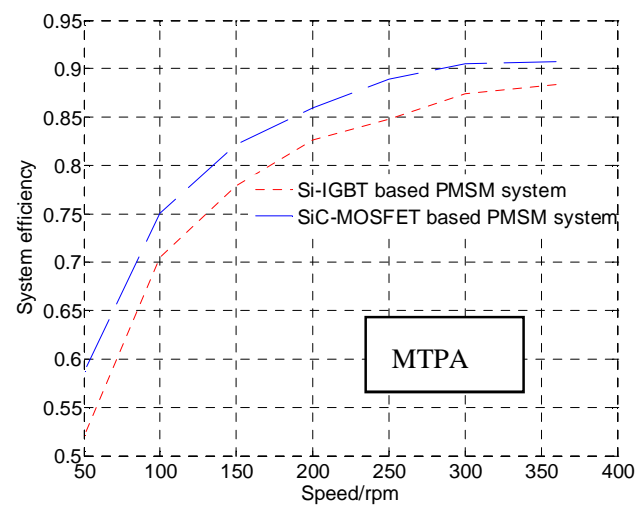

(a)

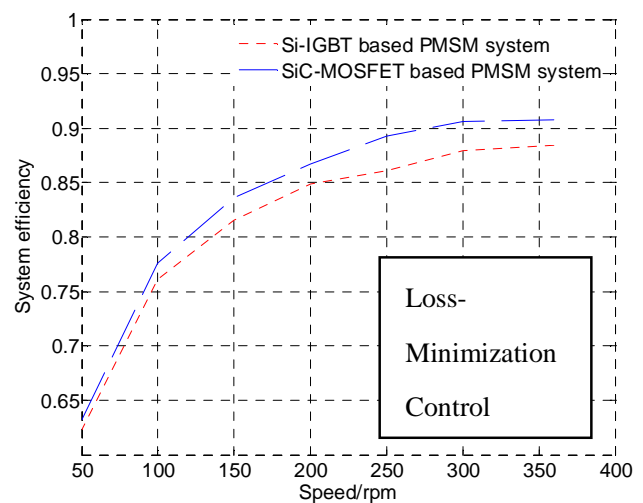

(b)

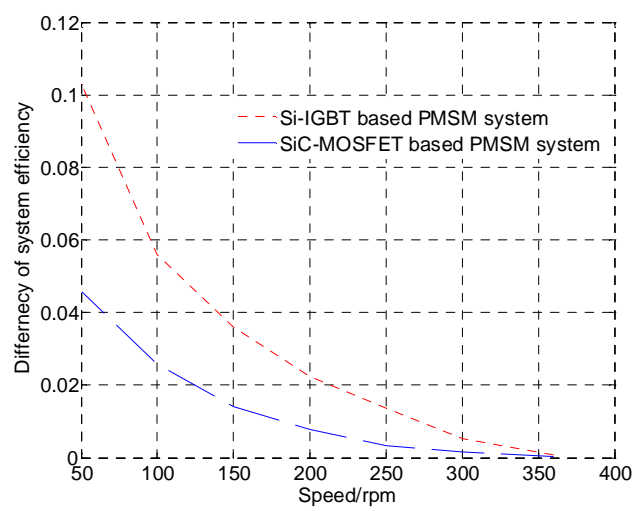

(c)

Fig.18 difference of system efficiency improvement between SiC-MOSFET based PMSM system and Si-IGBT based PMSM system. (a) System efficiency by MTPA control; (b) System efficiency by loss optimization control; (c) Difference of system efficiency improvement.

\section{Conclusion}

This paper has described the development of a novel loss minimization control strategy for EV in-wheel PMSM direct drive system which takes into account both the machine and inverter losses. The flux-weakening current is controlled according to the operating speed and the load conditions to minimize the copper and iron losses, thereby increasing the efficiency over the whole operation range. To obtain accurate inverter loss, this paper creates a nonlinear model of conduction and switching characteristics, and acquires accurate loss models of the inverter under SVPWM. Based on the inverter loss model, the developed control method adjusts the PWM frequency to the optimal value for overall system efficiency. Both theoretical analysis and experimental results show that the loss optimization control decreases the energy loss of in-wheel PMSM direct drive system without implications on stability. Such a strategy significantly improves the endurance mileage of EVs in one charge which is critical for future widespread EV technology market proliferation. 


\section{Acknowledgements}

This work was supported in part by the National Science Fund for Distinguished Young Scholars (No.51225702) and in part by the State Key Program of National Natural Science Foundation of China (No.51537002) and in part by the National key S\&T Special Projects of China (No.2012ZX045001051).

\section{References}

[1]. Fei Teng, Yunfei Mu, Hongjie Jia and etc. Challenges on primary frequency control and potential solution from EVs in the future GB electricity system. Applied Energy. 2016,23: 75-85.

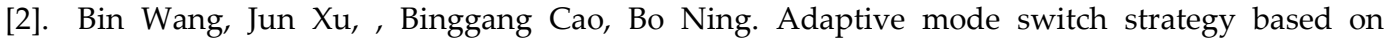
simulated annealing optimization of a multi-mode hybrid energy storage system for electric vehicles. Applied Energy. 2016,30:136-149.

[3]. Shuo Zhanga, Rui Xionga. Adaptive energy management of a plug-in hybrid electric vehicle based on driving pattern recognition and dynamic programming. Applied Energy. 2015, 155: 6778.

[4]. Hewu Wang, Xiaobin Zhang, Minggao Ouyang. Energy consumption of electric vehicles based on real-world driving patterns: A case study of Beijing. Applied Energy. 2015, 157: 710719 .

[5]. Lishan Suna, Yuchen Huanga, Shuli Liub and etc. A completive survey study on the feasibility and adaptation of EVs in Beijing, China. 2017, 138: 128-139.

[6]. Liang Lia, Xujian Lia, Xiangyu Wanga, Jian Songa, Kai Hea, Chenfeng Lia. Analysis of downshift's improvement to energy efficiency of an electric vehicle during regenerative braking. Applied Energy. 2015,176:125-137.

[7]. A. Arroyo, M. Manana, C. Gomez, I. Fernandez, F. Delgado, Ahmed F. Zobaa. A methodology for the low-cost optimisation of small wind turbine performance. Applied Energy. 2012,104:1-9.

[8]. Jemaa Brahmi, Lotfi Krichen, Abderrazak Ouali. A comparative study between three sensorless control strategies for PMSG in wind energy conversion system. Applied Energy. 2009,86:1565-1573.

[9]. S.-Y. Jung, J. Hong, K. Nam. Current minimizing torque controlof the IPMSM using Ferrari's method. IEEE Trans. Power Electron. 2013,28:5603-5617.

[10]. Xiaoxu Zhang, Xiao Liu, Jinglin Liu, Zhe Chen. Analytical Investigation on the Power Factor of a Flux-Modulated Permanent-Magnet Synchronous Machine. IEEE Transactions on Magnetics. 2015, 51: 73-76.

[11]. Wenliang Zhao, Thomas A. Lipo, Byung-Il Kwon. Dual-Stator Two-Phase Permanent Magnet Machines With Phase-Group Concentrated-Coil Windings for Torque Enhancement. IEEE Transactions on Magnetics. 2015, 51: 211-212.

[12]. Shi-Uk Chung, Ji-Won Kim, Yon-Do Chun, Byung-Chul Woo, Do-Kwan Hong. Fractional Slot Concentrated Winding PMSM With Consequent Pole Rotor for a Low-Speed Direct Drive: Reduction of Rare Earth Permanent Magnet. IEEE Transactions on Energy Conversion. 2015,30: 103-109.

[13]. Yong Liu, Chengde Tong, Jingang Bai, Shuang Yu, Weiming Tong, Weinong Fu. Optimization of an $80 \mathrm{~kW}$ Radial-Radial Flux Compound-Structure Permanent-Magnet Synchronous Machine Used for HEVs. IEEE Transactions on Magnetics. 2011, 47: 2399 - 2402

[14]. Yuan, W., Shao, P.W., Shu, M.C. Choice of Pole Spacer Materials for a High-Speed PMSM Based on the Temperature Rise and Thermal Stress. IEEE Transactions on Applied Superconductivity.2016, 26, 1109-1114.

[15]. Thomas F., Kay H. Design and optimization of an IPMSM with fixed outer dimensions for application in HEVs. IEEE International Electric Machines and Drives Conference, USA, 3-6, May 2009, pp: 887-892. 
[16]. Tiberiu Tudorache, Ion Trifu. Permanent-Magnet Synchronous Machine Cogging Torque Reduction Using a Hybrid Model. IEEE Transactions on Magnetics. 2012, 48: 2426-2437.

[17]. Li, F., Guo L.L., Zhe, Q., Wen, X.Y. Analysis of eddy current loss on permanent magnets in PMSM with fractional slot. Industrial Electronics and Applications (ICIEA), Auckland, New Zealand, 15-17, June 2015, pp: 1246-1250.

[18]. Morimoto, S., Tong, Y., Takeda, Y., Hirasa, T. Loss minimization control of permanent magnet synchronous motor drives. IEEE Trans.Ind. Electron.1994, 41, 511-517.

[19]. Estima, J.O., Marques Cardoso, A.J. Efficiency Analysis of Drive Train Topologies Applied to Electric/Hybrid Vehicles. IEEE Transactions on Vehicular Technology. 2012, 61, 1021-1031.

[20]. Pan, C.T., Sue, S.M. A linear maximum torque per ampere control for IPMSM drives over full-speed range. IEEE Trans. Energy Convers .2005, 20, 359-366.

[21]. Stumberger, B., Stumberger, G., Dolinar, D. Evaluation of saturation and cross-magnetization effects in interior permanent-magnet synchronous motor. IEEE Trans. Ind. Appl. 2003, 39, 1264-1271.

[22]. Jung, S.Y., Hong, J., Nam, K. Current minimizing torque control of the IPMSM using Ferrari's method. IEEE Trans. Power Electron. 2013, 28, 5603-5617.

[23]. Xiaofeng Ding, Min Du, Tong Zhou and etc. Comprehensive Comparison between Sic-mosfets and Si-igbts Based Electric Vehicle Traction Systems under Low Speed and Light Load. Energy Procedia, 2016, 88, 991-997.

[24]. A. Castellazzi, A. Fayyaz, G. Romano and etc. SiC power MOSFETs performance, robustness and technology maturity. Microelectronics Reliability, 2016, 58: 164-176.

[25]. Jeong, I., Gu, B.G., Kim, J., Nam, K., Kim, Y. Inductance estimation of electrically excited synchronous motor via polynomial approximations by Least Square Method. IEEE Trans. Ind. Appl. 2015, 51, 1526-1537.

[26]. Consoli, A., Scarcella, G., Scelba, G., Testa A. Steady-state and transient operation of IPMSMs under maximum-torque-per-ampere control. IEEE Trans. Ind. Appl. 2010, 46, 121-129.

[27]. Reza, F., Mahdi, J.K. High Performance Speed Control of Interior-Permanent-Magnet-Synchronous Motors with Maximum Power Factor Operations. IEEE Trans. Ind. Appl. 2003, 3, 1125-1128.

[28]. Uddin, M.N., Radwan, T.S., Rahman, M.A. Performance of Interior Permanent Magnet Motor Drive over wide speed range. IEEE Trans. Energy Conv. 2002, 17, 79-84.

[29]. Cavallaro, C., Tommaso, A. O., Miceli, R., Raciti, A., Galluzzo, G. R., Trapanese M. Efficiency Enhancement of Permanent-Magnet Synchronous Motor Drives by Online Loss Minimization Approaches. IEEE Trans. Ind. Electrons. 2005, 52, 1153-1160.

[30]. Uddin, M. N., Rebeiro, R. S. Online efficiency optimization of a fuzzy-logic-controller-based IPMSM drive. IEEE Trans. Ind. Appl. 2011, 47, 1043-1050.

[31]. Urasaki, N., Senjyu, T., Uezato, K. A novel calculation method for iron loss resistance suitable in modeling permanent-magnet synchronous motors. IEEE Trans. Energy Conversion. 2003, $18,41-47$.

[32]. Urasaki, N., Senjyu, T., Uezato, K. An accurate modeling for permanent magnet synchronous motor drives. 15th Annu. IEEE APEC, USA, 6-10, Feb 2000, pp: 387-392.

[33]. Bolognani, S., Peretti, L., Zigliotto, M., Bertotto, E. Commissioning of electromechanical conversion models for high dynamic PMSM drives. IEEE Trans. Industrial Electronics. 2010, 57, 986-993.

[34]. Ni, R.G., Xu, D.G., Wang, G.L., Ding, L., Zhang, G.Q., Qu, L.Z. Maximum Efficiency Per Ampere Control of Permanent-Magnet Synchronous Machines. IEEE Transactions on Industrial Electronics. 2015, 62, 2135-2143.

[35]. Xiaofeng Ding, Guanliang Liu, Min Du,Hong Guo. Chongwei Duan and Hao Qian. Efficiency Improvement of Overall PMSM-Inverter System Based on Artificial Bee Colony Algorithm Under Full Power Range. IEEE Transactions on Magnetics. 2016, 52: 1-4.

[36]. Chun Wanga, Rui Xionga, Hongwen Hea and etc. Efficiency analysis of a bidirectional DC/DC converter in a hybrid energy storage system for plug-in hybrid electric vehicles. Applied Energy. 2016, 183: 612-622 
[37]. Xiaofeng Ding, Min Du, Tong Zhou, Hong Guo, Chengming Zhang. Comprehensive comparison between silicon carbide MOSFETs and silicon IGBTs based traction systems for electric vehicles. Applied Energy. Available online 13 May 2016, ISSN 0306-2619, http://dx.doi.org/10.1016/j.apenergy.2016.05.059.

[38]. Xiaofeng Ding, Feida Chen, Min Du, Hong Guo, Suping Ren. Effects of silicon carbide MOSFETs on the efficiency and power quality of a microgrid-connected inverter. Applied Energy. Available online 13 October 2016, ISSN 0306-2619, http://dx.doi.org/10.1016/j.apenergy.2016.10.011.

[39]. Yamazaki, K., Seto, Y. Iron loss analysis of interior permanent-magnet synchronous motors-variation of main loss factors due to driving condition. IEEE Trans. Ind. Appl. 2006, 42, 1045-1052.

[40]. D. Grahame Holmes, Thomas A. Lipo. Pulse Width Modulation for Power Converters:Principles and Practice. In: Mohamed E. EI-Hawart, editors. New York: Wiley-IEEE Press; 2003, p. 276-353. 